\title{
ENTREPRENEURS' EXPLORATORY PERSEVERANCE IN LEARNING SETTINGS
}

\author{
Katrin Muehlfeld \\ Full Professor \\ Trier University, FB IV - Department of Business Administration \\ Universitätsring 15, 54286 Trier, Germany \\ Tel: +49 $651201-2682$ \\ E-mail: muehlfeld@uni-trier.de. \\ Diemo Urbig \\ Assistant Professor \\ University of Wuppertal, Schumpeter School of Business and Economics \\ Gaußstraße 20, 42119 Wuppertal, Germany \\ Tel: + 49202 439-3006 \\ E-mail: urbig@uni-wuppertal.de. \\ Utz Weitzel \\ Full Professor \\ Utrecht University, Utrecht University School of Economics, \\ Kriekenpitplein 21-22, 3584EC Utrecht, The Netherlands. \\ Tel: + 31302539810 \\ E-Mail: u.weitzel@uu.nl \\ Radboud University, Institute for Management Research, Department of Economics, \\ Thomas van Aquinostraat 5.1.26, 6525 GD Nijmegen, The Netherlands. \\ Tel: +31243616235 \\ E-Mail: u.weitzel@fm.ru.nl
}

Keywords: Perseverance; Entrepreneurial cognition; Exploration; Iowa Gambling Task. JEL classification: L 26, D 83

Acknowledgements: The authors acknowledge helpful comments from two anonymous referees, from the editor James Fiet, as well as from Arjen van Witteloostuijn and Toby Kretschmer. The authors particularly thank Codrin Kruijne for his help in the data collection and programming, as well as Antoine Bechara for providing normative sample data. Any remaining errors are our own. Katrin Muehlfeld and Diemo Urbig gratefully acknowledge financial support through the Antwerp Centre of Evolutionary Demography (ACED), which is financed by the Odysseus program of the Flemish Science Foundation (FWO). Diemo Urbig also acknowledges financial support from the Dr. Werner Jackstädt Foundation. 


\title{
ENTREPRENEURS' EXPLORATORY PERSEVERANCE IN LEARNING SETTINGS
}

\begin{abstract}
We introduce 'exploratory perseverance' as a novel construct that captures perseverant behavior in settings in which several alternatives can be explored and evaluated. We suggest that entrepreneurs display exploratory perseverance reflected by a tendency to keep exploring broader sets of alternatives, to adopt a parallel rather than sequential approach to trialand-error learning, and, after negative experiences with some alternatives, to be more inclined to give them a second chance. The results from an experimental study of 449 individuals participating in the Iowa Gambling Task indicate that more entrepreneurially experienced individuals display greater exploratory perseverance than those with little to no entrepreneurial experience.
\end{abstract}

\section{INTRODUCTION}

Scholars have documented substantial differences between entrepreneurs and nonentrepreneurs in the way they gather, process, and evaluate information and use it as input for their decision making and learning (e.g., Busenitz \& Barney, 1997; Simon, Houghton, \& Aquino, 2000; Keh, Foo, \& Lim, 2002; Weitzel et al., 2010). One characteristic that is typically ascribed to entrepreneurs is perseverance-commitment to a chosen course of action and its undaunted pursuit despite adversity (e.g., Baron, 2004; Markman \& Baron, 2003; Patel \& Thatcher, 2012; Van Gelderen, 2012; Verheul et al., 2012). Prior literature has indeed documented entrepreneurs' above-average willingness or capability to persevere in the face of adversity (Gimeno et al., 1997; Lowe \& Ziedonis, 2006; Markman et al., 2005), or as Holland and Shepherd recently put it, to decide, time and time again, to "continue to pursue a previously selected entrepreneurial opportunity" (Holland \& Shepherd, 2013: 333) against opposing motivational forces.

Strong evidence points to entrepreneurs' perseverance in pursuing a particular opportunity after they have committed to this opportunity by starting their business. Scholars have gained significant insights into antecedents (Gimeno et al., 1997; DeTienne et al., 2008; Holland \& Sheperd, 2013; Markman et al., 2005) and emotional and financial implications (e.g., 
Baum \& Locke, 2004; Markman et al., 2005; Sandri et al., 2010; Shepherd et al., 2009) of such perseverance. However, it remains an open question whether entrepreneurs are also more perseverant prior to having selected a particular opportunity. If several viable opportunities exist what does it actually mean to be perseverant? In entrepreneurial situations that require the exploration of several alternatives, for example, when choosing product or technology portfolios or business partners, do entrepreneurs quickly choose one path on which they "continue [...] regardless of counterinfluences or enticing alternatives" (Holland \& Shepherd, 2013: 333)?

As a first step toward addressing this research question, we investigate entrepreneurs' perseverance in a setting that captures important aspects of entrepreneurs' exploration of alternatives. This setting includes the structuring of information-gathering processes, learning from informational cues, (re-)evaluating available options, and the assessment of whether and when to exclude an option from further consideration (e.g., technology or product portfolio development, market segments). This setting is characterized by the possibility of making choices from a set of alternatives, where each choice carries both a payoff consequence and an informational cue. This informational cue points to the long-term payoff of the corresponding alternative, which may, however, diverge considerably from short-run payoffs. Repeat choices from the same set of all alternatives are feasible. At each step of this process, new information may prompt a re-evaluation of the options within the set. We refer to this type of setting as a concurrent learning setting because several options can be explored virtually in parallel. Because this setting substantially differs from those in previous studies of entrepreneurs' perseverance, we are able to shed new light on this concept.

For concurrent learning settings, we conceptually develop exploratory perseverance as a behavioral pattern. Exploratory perseverance implies choosing repeatedly, over a sequence of 
decision moments, from a broad choice set of alternatives, despite adverse experiences with some of them ('keep going back to other options, despite setbacks'). The second critical feature of exploratory perseverance is therefore a tolerance for negative outcomes when exploring alternatives, resulting in a broader set of informational cues to learn from, which — as a third feature-is coupled with a parallel approach to exploring alternatives. As such, exploratory perseverance involves sustained openness and deliberate choices that include seemingly inferior alternatives that are awarded a "second chance". Our basic proposition is that entrepreneurs exhibit such exploratory perseverance in concurrent learning settings. We concur that entrepreneurs are likely to continue sampling information about options that have previously produced negative results and do so to a greater degree than non-entrepreneurial individuals.

We assess these questions using an extensively validated neuropsychological framework for the study of exploratory decision making and learning — the Iowa Gambling Task (IGT) —and compare entrepreneurs' and non-entrepreneurs' decisions in performing this task. In so doing, we follow a nascent literature that analyzes entrepreneurial decision making using laboratory and experimental methods (e.g., Burmeister \& Schade, 2007; Haynie et al., 2012). We sample 449 individuals from two populations: students with varying levels of entrepreneurial experience, as well as a heterogeneous set of entrepreneurs and a matched sub-sample from the general population. The data and results robustly support our hypotheses.

This study makes two major contributions. First, it adds to the literature on entrepreneurial perseverance/persistence ${ }^{1}$ by (i) conceptualizing exploratory perseverance as a novel theoretical construct, (ii) by pointing out the possibility of distinguishing between types of

1 The terms 'perseverance' and 'persistence' are sometimes but not always used interchangeably in the literature in order to denote continued pursuit of a course of action despite opposition. In order to avoid conceptual ambiguities, we use the term 'perseverance' to capture this notion. 
perseverance and especially the distinction between referring to an individual action or a behavioral pattern, and (iii) by suggesting differences in the phase-specific relevance of these types. Our study enables future research to more accurately conceptualize and analyze the contexts and ways in which we expect entrepreneurs to persevere. Furthermore, the results from this study demonstrate that differences in perseverance can be detected outside the entrepreneurial venture when zooming in on selected features of entrepreneurial ventures, such as learning opportunities in explorative settings. We find that perseverance is a distinct feature of entrepreneurs' decision making in a context that is largely devoid of factors such as switching costs, vested interests, social norms, and so on. This suggests that exploratory perseverance is rather fundamental in nature and not solely a context-contingent characteristic of entrepreneurs. Our findings therefore help to reconcile prior research on entrepreneurs' perseverance that did not find evidence of entrepreneurs' stronger perseverance in settings outside of the entrepreneurial venture (e.g., Burmeister \& Schade, 2007; Sandri et al., 2010).

Second, this study adds to research on entrepreneurial learning, which investigates the how entrepreneurs "acquire and transform information and experience" (Corbett, 2007: 97). We show how entrepreneurs' learning differs from that of others: entrepreneurs' are more likely to continue sampling information about options that have previously produced negative results. That is, they are "once bitten, twice still not shy". Thereby, this study identifies entrepreneurs' exploratory motivation as a complementary driver of their perseverance, adding to individual characteristics such as elevated overconfidence (Baron, 1998; Busenitz \& Barney, 1997; Forbes, 2005; Koellinger et al., 2007; Simon et al., 2000; Wu \& Knott, 2006), reduced loss aversion (Burmeister \& Schade, 2007), and related personality characteristics, for example, neuroticism (Bibby \& Ferguson, 2011; Patel \& Thatcher, 2012), which have been discussed in other contexts. 
Rather than simply being less averse to losses, their persistence when faced with adversity may partially result from accepting losses as an inevitable part of exploratory learning. Thus, perseverance with a venture may result from an exploration motive.

\section{THEORY AND HYPOTHESES}

\section{Foundations of entrepreneurs' decision making and learning: Perseverance and exploration}

Intragroup heterogeneity notwithstanding, marked differences appear to exist between the typical patterns of the decision making, thinking, and learning of entrepreneurs and nonentrepreneurs (for a recent overview, see Shepherd, Williams, \& Patzelt, 2015). Perseverance is one such feature that is often viewed as particularly characteristic of entrepreneurs' decision making and learning (e.g., Baron, 2004; Markman \& Baron, 2003; Patel \& Thatcher, 2012; Van Gelderen, 2012; Verheul et al., 2012). Perseverance can generally be defined as the pursuit of a chosen course of action in spite of adversity and counterinfluences. ${ }^{2}$ Scholars have indeed empirically documented entrepreneurs' above-average willingness or capability to persevere when faced with obstacles (Gimeno et al., 1997; Lowe \& Ziedonis, 2006; Markman et al., 2005). Lowe and Ziedonis (2006), for example, found that entrepreneurs continued development efforts for longer periods of time when faced with negative outcomes than established firms did. Prior behavioral evidence of entrepreneurs" particular adeptness at "sticking to it" has primarily been obtained for the specific context of entrepreneurial venture operations, i.e., after entrepreneurs have already committed themselves to a particular opportunity. Such a focus allows little

\footnotetext{
$2 \quad$ While our definition of 'perseverance' is generic, Holland and Shepherd (2013) provide a similar definition applied specifically to the entrepreneurial context. They define entrepreneurial persistence as "when the entrepreneur chooses to continue with an entrepreneurial opportunity regardless of counterinfluences or enticing alternatives" (Holland and Shepherd, 2013: 331).
} 
inference as to whether perseverance is a context-independent, fundamental characteristic of entrepreneurs.

Evidence from the few studies that have investigated factors related to entrepreneurs' perseverant behavior in contexts other than entrepreneurial venture operations have mostly failed to yield significant support for perseverance as a distinct, general characteristic of entrepreneurs vis-à-vis non-entrepreneurs. For example, Burmeister and Schade (2007) analyzed, in an experimental setting, whether entrepreneurs were affected by status quo bias in their decision making, with status quo bias being defined as "the tendency to select a previously chosen alternative disproportionately often" (Burmeister \& Schade, 2007; 340). While they found support for this basic hypothesis, entrepreneurs were not more susceptible than students and less susceptible than bankers. Sandri and co-authors (2010) experimentally analyzed disinvestment choices of enterprising and other individuals in the laboratory as "a problem of optimal stopping, stylizing a context-free choice to abandon a project for a constant termination value" (Sandri et al., 2010: 35). They found evidence of 'psychological inertia' — which can be interpreted as a form of perseverance — in the sense that participants tended to "hold on to a losing project" (Sandri et al., 2010: 30) for too long. Holding on for "too long" was assessed in comparison to a rational benchmark in a real-options framework that incorporated a rational value for waiting. However, there was no significant difference between entrepreneurs and non-entrepreneurs in terms of delayed exit from the project.

We argue that it would be premature to conclude from these studies that above-average perseverance is not a general characteristic of entrepreneurs vis-à-vis non-entrepreneurs. Instead, we suggest that previous insignificant results may stem from too narrow an interpretation of the perseverance construct, as well as from the specific characteristics of the lab settings employed 
in these studies. 'Real-world' entrepreneurial venture operations, in which superior perseverance of entrepreneurs has been documented, are characterized by two core features: First, time and time again, entrepreneurs are faced with the choice between two options: stay the course after having committed to a particular opportunity or exit and "abandon the effort" (Shane, Locke, \& Collins, 2003: 271). One of the choices, to exit, is largely irreversible. The entrepreneur can opt to exit only once (at least relating to a specific venture). Second, as Holland and Shepherd (2013) argue, if the entrepreneur repeatedly chooses to persist with the venture, s/he obtains new information and feedback and thereby continues to learn something (e.g., about the viability of the venture). Thereby, learning may also include learning about the specific path or strategy a venture follows, that is, learning to select an optimal strategy from a multitude of strategic options.

Prior lab studies that failed to find evidence of entrepreneurs' superior perseverant behavior have zoomed in on the first of these two features and have modeled decisions between alternatives in which one of them was irreversible (exit). Therefore, the second property related to information acquisition, feedback, and learning about an initially unknown state was either absent or marginalized in the lab settings employed in earlier work. We complement these prior studies by focusing on this second core feature.

Specifically, we investigate whether entrepreneurs display above-average perseverance in 'concurrent learning settings' that involve choices from a set of alternatives (i) where each choice carries both a payoff consequence and an informational cue about the long-term benefit of the corresponding alternative, (ii) where repeat choices from the same set of all alternatives are feasible (no irreversible option included), and (iii) where there may be a trade-off between shortrun payoffs and long-run payoffs from the various alternatives. At each step of this learning 
process, new information may prompt a re-evaluation of the options within the set. Business practice is rich in contexts that fall into this category during all stages of the entrepreneurial process, from opportunity identification to exploitation. Early venture stages may be particularly rife, for example, when entrepreneurs consider paid employment (continuation, scaling, re-entry) vis-à-vis episodic self-employment (e.g., Parker, 2004; Patel \& Thatcher, 2012), time allocation between a new venture and paid employment (Burmeister-Lamp et al., 2012), and the selection of technology or product portfolios.

Previous entrepreneurship research on perseverance (e.g., Holland \& Shepherd, 2013; Gimeno et al., 1997) usually relates to persevering with a business that the entrepreneur has already started and where no viable alternative other than exiting the chosen business exists. Corresponding perseverance is affected by self-justification and switching costs and so on. Such perseverance is, by definition, absent from the type of concurrent learning setting that we study, where several alternatives but no option to exit exist. Complementing this type of setting by considering concurrent learning settings, we explicitly capture behavioral patterns that accord with entrepreneurs' typical approach to information acquisition and processing.

In concurrent learning settings, perseverance can assume different meanings. First, perseverance may capture a behavior that implies the repeated, successive choice of the same alternative in spite of the possible negative information cues and experiences with this alternative and in spite of other readily available options. Relating to the general definition of perseverance as commitment to a chosen course of action and its pursuit in spite of adversity, the activity in question is interpreted as essentially equivalent to the chosen alternative. Hence, we refer to this type of perseverance as narrow perseverance. 
Second, if the equivalence between the activity and the alternative is relaxed, perseverance in such a concurrent learning setting can also refer to the continued pursuit of a course of action that implies retaining, over a sequence of decision moments and despite adverse experiences with at least some of them, a broad choice set of alternatives, as opposed to narrowing down the choice set early in the process. A choice set is defined as the set of alternatives from among the initially available alternatives that a person does not exclude from his or her information search. We refer to this specific behavioral pattern as exploratory perseverance. Unlike narrow perseverance, i.e., sticking to a particular alternative ('keep going with the same option, despite setbacks') from an early stage of the exploration process onwards, exploratory perseverance aims at continuing to try and learn for longer ('keep exploring options, despite setbacks'). ${ }^{3}$

Hence, the two types of perseverance that we focus on and which apply to concurrent learning settings are conceptually different from and complement prior conceptualizations of perseverance. For example, in business reality, an entrepreneur might persist with one business that he/she has already started while at the same time continuing to explore other possibilities (exploratory perseverance) related to, for example, a potential second business opportunity. Portfolio entrepreneurs or, generally, entrepreneurs that persist with one particular "business" but are simultaneously inclined to consider other new products or markets are examples that illustrate the complementarity of the concept of exploratory perseverance with perseverance as it has previously been studied in the literature.

In fact, entrepreneurs have been shown to have a greater inclination to explore many

\footnotetext{
3 As such, exploratory perseverance is related to research on feedback-based learning that has found interpersonal differences in learning during noisy tasks in which feedback has a reduced value (Hogarth \& Villeval, 2010): While some individuals exit early because they believe further signals have no informative value, others persist and keep collecting more information by observing more signals across time.
} 
alternatives (Baron, 2004; Busenitz, 1996) and to favor experimentation over exploitation (Crossan, Lane, \& White, 1999; Busenitz, 1996; Wang, 2008). A preference for exploratory perseverance in concurrent learning settings would be consistent with entrepreneurs' observed tendency to continue to believe in the potential value of several alternatives from a range of options, even when negative feedback during the exploration of the particular alternative signals its potential inferiority (Baron \& Markman, 2003; McMullen \& Shepherd, 2002; Corbett, 2007). Non-entrepreneurs, in contrast, are more easily convinced that an option in question is not worth pursuing and are, therefore, more likely to exclude it from further consideration. The same objective failure probabilities are, thus, less likely to deter entrepreneurs from exploring alternatives (McMullen \& Shepherd, 2002; Corbett, 2007). As such, perseverance motivated by a need for exploration reflects both sustained openness and a tolerance for negative experiences, that is, a willingness to consider seemingly inferior alternatives for a longer time period. ${ }^{4} \mathrm{Such}$ behavior could also explain prior observations that entrepreneurs seem to be comparatively slow at incorporating information (Parker, 2006): they require more information (for example, on costs and benefits of individual alternatives) before they are satisfied with the amount and depth of information such that they actually modify their decisions. Instead of assuming that they learn less, we might interpret the observation as entrepreneurs aiming at more information to guide their decision making. In other words, they persevere for longer in their exploration.

\section{Broad Choice Set vs. Concentration of Choices}

The typical approach of entrepreneurs' to information acquisition and processing has been described as being geared towards examining greater numbers of distinct alternatives (e.g.,

\footnotetext{
$4 \quad$ A broader choice set could also result from a perception of alternatives as equally good. A tolerance for negative outcome histories could also lead to a perpetual repetition of the same inferior behavior. Thus, both behaviors are simultaneously needed for a behavioral pattern of exploratory perseverance to emerge.
} 
Busenitz, 1996; Corbett, 2007; Crossan et al., 1999; Wang, 2008). Recent studies into their shared cognitive, affective, and motivational tendencies underpin this view. From a cognitive perspective, researchers have argued that entrepreneurs differ from non-entrepreneurs in their frames, their learning from, thinking about, interpreting, and exploring the world (e.g., Baron, 1998, 2004; Cooper et al., 1995; Corbett, 2007; Gaglio \& Katz, 2001; Krueger, 2003). Many of the identified differences are consistent with keeping a broader rather than a narrower choice set. Gaglio and Katz (2001) and Gaglio (2004), for example, suggest that entrepreneurs' cognition is characterized by chronic alertness, which makes them particularly acutely aware that existing means-ends frameworks may be inappropriate. Studies into entrepreneurs' cognitive breadth (Kim et al., 2010) and their ability to identify potentially complex patterns in business models (Baron \& Ensley, 2006; Baron \& Ward, 2004) suggest that more entrepreneurially experienced individuals are better able to cognitively deal with complex patterns and to keep a larger number of potentially conflicting ideas in play.

Evidence from studies that focus on affect or integrate emotional aspects related to entrepreneurs' decision making into the cognitive perspective (e.g., Hayton \& Cholakova, 2012) also lends support to the notion that entrepreneurs might retain a broad choice set. Studies in this line of research have, for example, found that entrepreneurs tend to be high in dispositional positive affect, that is, they expect positive moods and emotions often and in a wide range of contexts (Baron et al., 2011; Baron et al., 2012). Dispositional positive affect expands the scope of an individual's attention, cognition, and action (Baron et al., 2012; Frederickson \& Barnigan, 2005). Positive affect, in general, broadens the mindset by stimulating considerations of a wider range of possibilities and actions (Frederickson, 2001) and reduces the selectivity of attentional filters (Rowe et al., 2007). 
Finally, research on the foundations of entrepreneurs' motivational systems is also indicative of a greater width of choice sets. In particular, scholars have drawn on regulatory focus theory (Carver \& Scheier, 1998; Higgins, 1997, 1998) to explain differences between entrepreneurs and non-entrepreneurs in the processes of setting goals, selecting means, and evaluating progress towards goal attainment (Baron, 2004; Brockner et al., 2004). According to this perspective, goal-directed behavior is governed by two motivational systems (Higgins, 1997, 1998). The prevention system features an orientation towards 'oughts' and induces people to aim at avoiding mistakes by abstaining from actions that might produce negative outcomes (Pham \& Higgins, 2005). The promotion system implies an orientation towards ideals and encourages individuals to generate and consider a larger set of alternatives, out of an eagerness to seize opportunities (Liberman et al., 2001; Pham \& Higgins, 2005). Entrepreneurs appear to share a tendency towards a 'dispositional' promotion focus and the associated behaviors (Alvarez \& Busenitz, 2001; Bryant, 2007; Shane \& Venkataraman, 2000).

In sum, we expect that entrepreneurs' shared affective, cognitive, and motivational tendencies manifest themselves in a concurrent learning setting in a continued exploration of a broad set of alternatives rather than a quick narrowing down of their choice set to a small subset.

Hypothesis 1: In a concurrent learning setting, entrepreneurs are more likely than nonentrepreneurs to retain a broad choice set. That is, they do not concentrate on a narrow choice set early on.

\section{Parallel vs. Sequential 'Trial and Error'}

Retaining, despite setbacks, a broad choice set can be achieved by using a range of different temporal selection strategies. To illustrate this, let us assume, first, that the set of available alternatives initially consists of alternatives A, B, C, D, from which information can be 
sampled during twelve decision events. Second, let us assume that all four alternatives are explored to a maximum (each of them is selected three times). Then, a range of temporal selection strategies is possible, with the two extreme points being (i) a (comparatively) 'parallel' approach to 'trial-and-error' (e.g., A, B, C, D, A, B, C, D, A, B, C, D), which entails frequent switching in one's information sampling between the different alternatives, and (ii) a (comparatively) 'sequential' approach to 'trial-and-error' (e.g., A, A, A, B, B, B, C, C, C, D, D, D), which entails less switching during the exploration process (e.g., Eggers \& Green, 2012). In this example, parallel 'trial-and-error' yields quicker insights into the cross-sectional relationships between the four alternatives and represents a more global perspective. Sequential 'trial-and-error' is a more focused approach for quicker comprehension of (local) information about specific characteristics and their dynamics. Sequential 'trial-and-error', however, allows for global comparisons across alternatives only at a much later stage.

Direct empirical evidence on whether entrepreneurs generally tend to use a parallel or sequential 'trial-and-error' approach is limited. A few studies address related issues, however. Literature on entrepreneurs' distinct skills offers indirect evidence. Distinct cognitive and affective skills appear to contribute to this greater likelihood of and preference for parallel tasking as well.

Studies into entrepreneurs' cognitive breadth (Kim, Clelland, \& Bach, 2010) and their ability to identify potentially complex patterns in business models (Baron \& Ensley, 2006; Baron $\&$ Ward, 2004) suggest that entrepreneurs and, especially, more experienced entrepreneurs are better able to cognitively deal with complex patterns and to keep a larger number of potentially conflicting ideas in play. These cognitive tendencies enable and possibly predispose them to favor parallel 'trial and error' because a sequential approach can be interpreted as a coping 
mechanism in response to excessive strain on information processing capacities.

Distinct affective components of entrepreneurial learning, such as higher comparative optimism (cf. Ucbasaran et al., 2010) and higher dispositional positive affect (Baron et al., 2011, 2012), appear to further add to greater cognitive flexibility and scope of attention. Strong, positive affect has been shown to induce cognitive strategies that allow for coping with higher stress levels (Carver \& Scheier, 2001), which are associated with simultaneous rather than sequential processing.

Motivational factors related to a possible dispositional promotion focus (Alvarez \& Busenitz, 2001; Bryant, 2007; Shane \& Venkataraman, 2000) offer tentative support for entrepreneurs' simultaneous exploration. A promotion focus has been associated with a more global and 'top-down' approach to the searching, perception, and processing of information (Förster and Higgins, 2005; Pham \& Higgins, 2005; Semin et al., 2005) and with more varietyseeking in search processes as a way of capturing additional opportunities (Pham \& Higgins, 2005). Zhu and Meyers-Levy (2007) found that individuals engaged in either one of two modes of information processing, depending on their regulatory focus. Promotion-focused individuals tended towards relational processing, that is, the integration of shared aspects and abstracting from differences among dissimilar pieces of information (Hunt \& Einstein, 1981; Johnson, 1984). Prevention-focused persons were likely to adopt item-specific processing, which refers to generating precise, context-specific associations for each item in isolation of others (Hunt and Einstein 1981). Because parallel 'trial and error' generates relational information more quickly than a sequential approach, it is more consistent with a promotion focus.

Overall and based on previous research, we expect the following:

Hypothesis 2: In a concurrent learning setting, entrepreneurs are more likely than non- 
entrepreneurs to use a parallel rather than sequential 'trial and error' approach.

\section{Tolerance for Negative Experiences}

Tolerance for negative experiences is a key element of perseverance. When applied to exploratory perseverance, this characteristic implies that seemingly inferior alternatives according to current information and experience history — are not dropped from a choice set at a too-early stage. Prior studies offer indirect evidence — through cognitive, affective, and motivational lenses - that suggests that entrepreneurs may possess a superior tolerance for negative experiences.

First, from cognitive and affective viewpoints, Parker (2006) found that entrepreneurs were generally comparatively slow in adjusting their expectations in light of new information. More specifically and relating to experiencing and processing negative information, scholars have found that entrepreneurs tend towards a substantially rosier outlook on the future, as indicated by stronger (over-)optimism and comparative optimism (Ucbasaran et al., 2010), as well as dispositional positive affect (Baron et al., 2011, 2012). Interpersonal differences in dispositional affect, for example, influence how information is encoded into memory, implying differences in what is later available for retrieval and use in decision making (Eich, 1995). High levels of positive affect are associated with a tendency to memorize and remember positive information. As a result, biased samples of information may be stored and later used in decision making (Miller, 2008), for example, relating to ideas for a new product (Baron et al., 2012). Also, strong positive affect has been shown to induce cognitive strategies that allow for coping with the higher stress levels (Carver \& Scheier, 2001) associated with negative experiences.

Second, from a motivational angle, research into the effects of regulatory focus on the nature and magnitude of emotional reactions to success and failure (e.g., Brockner \& Higgins, 
2001) tentatively suggests that entrepreneurs may be relatively more tolerant and forgiving of negative experiences. Halamish and colleagues (2008) report that individuals with a prevention focus were more loss-averse. Particularly in ambiguous environments, they restrict the set of alternatives they consider more quickly and strongly in response to a history of negative experiences (Pham \& Chang, 2010). Promotion-focused individuals, in turn, are more varietyseeking in their search processes as a way of capturing additional opportunities (Pham \& Higgins, 2005). Hence, to the extent that entrepreneurs tend towards a promotion focus (e.g., Bryant, 2007), we expect that the same objective failure probabilities deter entrepreneurs less than non-entrepreneurs from exploring alternatives that performed poorly in the initial stages of the information-sampling process. This proposition is also consistent with evidence that entrepreneurs are less concerned with avoiding failure and instead focus on potential success in a multitude of options (McMullen \& Shepherd, 2002). This is also consistent with conceptualizations of entrepreneurial learning as being anticipatory and oriented towards future possibilities rather than past patterns (Crossan et al., 1999).

In sum, we expect that entrepreneurs have a stronger tendency to continue sampling information about alternatives with inferior outcome histories. That is, we expect them to be more likely to give 'second chances'.

Hypothesis 3: In a concurrent learning setting, entrepreneurs exhibit greater tolerance for negative experiences than non-entrepreneurs.

\section{METHODS}

\section{Experimental design: The IOWA Gambling Task}

The IOWA Gambling Task (IGT) is an established, extensively validated, easy-toadminister, and unobtrusive clinical measurement instrument from the domain of 
neuropsychology (e.g., Bechara \& Damasio, 2005; Dunn, Dalgleish, \& Lawrence, 2006). The IGT is rather abstract and without particular reference to the entrepreneurial context. Because scholars have shown that thoughts may become increasingly channeled by past experience (Shepherd et al., 2003), this contextual independence allows us to draw a meaningful comparison between more and less entrepreneurially experienced individuals. The IGT was designed to quantify differences between individuals regarding the degree to which their learning and decision making are insensitive towards negative outcomes ('punishment') and thus malleable based on experience and new information (Bechara et al., 1994). The IGT resembles a situation in which individuals must learn, through trial-and-error-based exploration, that an option that initially — due to relatively higher immediate payoffs — appears advantageous is, in the long run, inferior because of occasionally high losses.

The IGT's specific experimental design involves four decks of cards (A, B, C, D), which are placed face down. Individuals pick one card at a time from one of the decks and turn it around to see two values (see Figure 1). The first value indicates the immediate and regular gain associated with a deck; the second value indicates a complementary, uncertain, and irregular loss. Two decks (A, B) yield high immediate and regular gains but, at unpredictable points in time, they also include high penalties, turning the net benefit of these decks negative. For decks $\mathrm{C}$ and $\mathrm{D}$, the immediate gains and occasional penalties are smaller than for decks $\mathrm{A}$ and $\mathrm{B}$, but the occasional penalties are sufficiently small to result in a positive net payoff for decks C and D. Because the positive values are constant, learning in the IGT relates to the frequency and level of penalties. The detailed schedules of payoffs can be found in Bechara et al. (1994). Individuals start without any information about the decks; they may switch at any point in time and as often as they wish. They do not know in advance the number of decisions they make, but the standard 
version of the game ends after an individual has made 100 selections in total. Note that the design of the IGT penalizes insensitivity towards negative outcomes. Individuals with such a behavioral pattern underperform in the IGT. Because the IGT, therefore, does not reward exploratory perseverance in performance terms, it represents a conservative test of our hypotheses.

In this study, we used an online implementation of the standard instructions for the computerized version of the IGT, as developed and used in the prior research (Bechara et al., 1999; Bechara et al., 1994). To prevent location effects, the decks A, B, C, D were presented in a random order on the screen for every subject (and not labeled A, B, C, D). The task was incentivized by way of lottery tickets (Starmer \& Sugden, 1991). Each point earned in the IGT was converted into a lottery ticket. The number of points therefore directly determined the probability of winning a prize. Because subjects could lose points, we provided them with an initial endowment of 2,000 points to ensure non-negative final scores. For the student sample, there were three lotteries of 150 Euros each. In the entrepreneurs' subsample, there were two lotteries: a candlelit dinner ( $\sim 200$ Euros) and a choice between Russian caviar and French champagne ( $\sim 100$ Euros).

To facilitate a more in-depth interpretation of our experimental findings, we briefly summarize the basic neuropsychological interpretation of individual differences in the IGT. The IGT is often used to test the somatic marker hypothesis (SMH) (Bechara et al., 1994; Damasio, 1994). The SMH suggests that experience of reward and punishment evokes bioregulatory processes. Somatic markers are body-related responses that hallmark emotions and are reflective of these bioregulatory processes, which guide behavior in such a way that negative experiences are avoided in the long term (Bechara et al., 1997; Bechara \& Damasio, 2005; Bechara, Tranel, 
\& Damasio, 2000). In healthy individuals, somatic markers represent the link between past emotional reactions to negative stimuli on the one hand and future responses on the other hand. In patients with certain brain lesions, this link is broken. Specifically, individuals with lesions in the ventromedial prefrontal cortex (VMPFC) and in the bilateral amygdala are argued to suffer from disrupted functioning of somatic markers (Bechara et al., 1994; Damasio, 1994; Horstmann et al., 2012; Bechara et al., 1996). ${ }^{5}$ The IGT has been used to test this hypothesis.

Studies using the IGT have demonstrated that patients who show severe impairment in real-life decision making (Damasio, 1994; Bechara et al., 1998; Eslinger \& Damasio, 1985) indeed do not sufficiently respond to the negative experiences in the IGT. Despite normal intellect, memory, and problem-solving abilities, these patients displayed very low performance on the IGT. While the details regarding the somatic marker hypothesis are still subject to ongoing debate ${ }^{6}$, the IGT's ability to discriminate between people with more or less persistence in response to negative experiences is well-established. The benefits of using the IGT in order to uncover differences between subgroups of healthy people are also illustrated by a growing stream of research that relates IGT performance to personality traits (Franken \& Muris, 2005; Harman, 2011) and demographic features (d'Acremont \& Van der Linden, 2006).

\section{Sample}

Our sample is composed of 349 students with varying levels of entrepreneurial experience (Sample 1) and 100 non-student individuals (Sample 2). Sample 2 consists of 'real' entrepreneurs, individuals who have gained actual experience in running their own ventures, and

\footnotetext{
$5 \quad$ Sometimes, the IGT is employed in combination with the analysis of skin conductance responses (SCRs) as physiological indicators of the arousal accompanying bioregulatory processes. Depending on the brain region affected by lesions, individuals underperforming on the IGT fail to produce both reactive and anticipatory SCRs (amygdala patients) or may generate reactive but not anticipatory SCRs (VMPFC patients) (Bechara et al., 1996; Bechara \& Damasio, 2005).

$6 \quad$ Such details include, for example, the complementary roles of various other brain regions in the generation of somatic markers (e.g., Bechara et al., 1999, see also Dunn et al., 2006; Toplak et al., 2010).
} 
a matched group of people from the pooled normal data published in the Iowa Gambling Task Manual (Bechara, 2007). While the student sample is relatively homogeneous and large, providing substantial statistical power for our hypothesis tests (cf. Bönte et al., in press, Urbig et al., 2012), the second sample offers more heterogeneity across entrepreneurs and nonentrepreneurs and therefore more insight into the extent to which conclusions drawn from the student sample can be generalized to other populations. Our sample sizes are similar or even exceed (for Sample 2) the samples sizes reported in comparable IGT studies (e.g., d'Acremont \& Van der Linden, 2006; Harman, 2011) and in incentivized experimental studies in entrepreneurship research (e.g., Gatewood et al., 2002; Sandri et al., 2010).

The student sample is drawn from a database of 1,200 students who had registered for participation in laboratory experiments at Utrecht University, in the Netherlands. Each student received an email with an invitation to participate in a web-based experiment, followed by an online survey (see Gatewood et al., 2002, on web-based experiments in entrepreneurship research). Together with the invitation, each recipient received a unique login code that provided one-time access to the website with the IGT task. Three hundred and fifty-eight students completed both the IGT and the subsequent survey. We omitted nine persons who waited more than five minutes for at least one decision, suspecting that they were distracted. ${ }^{7}$ The final student sample contains 349 students, who participate in about 39 distinct study programs ranging from 'Economics' to 'Geo Sciences' and 'Law'. Sixty-four percent of the students are female, and the average age is 23.6 years.

Data on entrepreneurs for the non-student sample were collected using a mobile lab (e.g., Harrison et al., 2002) at an annual entrepreneurship event in Utrecht, the Netherlands ("Week

\footnotetext{
Results do not change substantially, and conclusions are the same when including these nine observations.
} 
van de Ondernemer"). ${ }^{8}$ Since its foundation in 1998, this entrepreneurship event has emerged as the major annual venue for entrepreneurs in the Netherlands. It represents a mixture between a platform for networking, presentations, and workshops for entrepreneurs and attracts several thousand entrepreneurs each year. We followed a similar procedure as Elston and Audretsch (2011). We approached participants at random and asked whether or not they had ever started their own new business and, thus, had substantial experience as entrepreneurs. These entrepreneurs were guided to a booth to complete the IGT on a laptop and answered a brief electronic questionnaire. Among the entrepreneurs' sample, 24 percent had previously been entrepreneurs but did not own their company anymore. Seventy-six percent were still owners at the time of the data collection. Their businesses had an average age of 8.7 years and an average size of 27 employees. Entrepreneurs' data were matched with the pooled normal data ${ }^{9}$ published in the IGT manual (Bechara, 2007), kindly provided by Antoine Bechara. Observations from the normative sample were matched based on 'age' and 'gender' at a ratio 3:1. We do not have specific information on the entrepreneurial experience of these matched data points. However, based on the fact that the normative sample reflects the general population, we are confident that the level of entrepreneurial experience in the matched normative sample is much lower than in the sample of entrepreneurs. Overall, 24 percent were women, and the average age was 39.7 years.

\section{Dependent variables}

\section{Performance}

The standard criterion used for comparisons of performance in the IGT (e.g., Bechara et

\footnotetext{
$8 \quad$ Further information is available from the website of the event: http://www.weekvandeondernemer.nl. $9 \quad$ The underlying design differs slightly from the original IGT but provides comparable behavioral responses (Bechara et al., 2000).
} 
al., 1999; Chiu and Lin, 2007) is the frequency of choices from objectively advantageous decks. Decks A and B are the ex-post 'disadvantageous decks' with high immediate gains and steady payoffs but occasionally very high losses. Decks C and D are the ex-post 'advantageous decks' with moderate immediate gains and steady payoffs but only occasional small losses. The more participants select from decks A and B, the poorer their final performance. At the beginning of the IGT, participants do not know which card decks represent decks A, B, C, and D. The speed with which they learn to concentrate on decks $\mathrm{C}$ and $\mathrm{D}$ reflects the degree to which they actually shy away from decks that generate strong negative experiences (A and B). Following standard practices in evaluating the IGT, we evaluate the relative frequency of selections from decks $\mathrm{C}$ and D over blocks of 20 decisions (e.g., Bechara et al., 2000).

\section{Broad choice set vs. concentration of choices}

In order to assess the degree to which participants continued to explore a broad set of alternatives over the course of the total 100 choices they made, we measured the degree of concentration of selections in the IGT by calculating the Herfindahl index (HI) of subjects' choices. The HI is a widely used continuous measure of concentration (e.g., Hitt et al., 2001), which in our analysis, captures the concentration of choices across all available decks (A, B, C, D). We adopt the frequently used logarithmic form (e.g., Makhija, 2003). As with our measurement of performance, we also calculated the concentration ratio for each block of 20 decisions ('card draws'). Alternative measures to the HI, such as the concentration ratio (Davies, 1979), yield equivalent results.

\section{Parallel vs. sequential 'trial and error'}

We assessed the degree to which participants' adopted a parallel rather than sequential approach by measuring the extent of switching back and forth between alternatives. A parallel 
approach entails more frequent switching than a more sequential approach. We operationalized this by using a binary variable for Switching (SW) between decks. We computed a dummy indicating the choice of a deck that differed from the immediately preceding deck. This variable is undefined for the first deck choice.

\section{Tolerance for negative experiences}

The degree to which individuals tolerate negative experiences is measured by the extent to which they deviate from maximizing expected future payoffs based on their specific and imperfect information resulting from their previous selections. Specifically, we calculated the Relative disadvantage (RDA) of a deck selected in a particular decision. The RDA is the absolute difference between the past average payoff of this deck (e.g., A) and the maximum past average payoff of all card decks (A, B, C, D). To ensure comparability, we calculate this variable only for decisions where an individual has previously had experiences with all four decks (i.e., has drawn a card from each deck at least once). ${ }^{10}$ RDA is either zero or positive. Positive values indicate that selecting from another deck would have increased an individual's expected payoff. Zero indicates that the selected deck maximizes the expected payoff. ${ }^{11}$

\section{Independent variable: Entrepreneurial experience}

Within the student sample, we measured entrepreneurial experience following Zhao et al. (2005) by asking — on a five-point scale ranging from very low (1) to very high (5) — about the participants' levels of experience in various entrepreneurship-related activities, such as starting a business. We added an item about experience in being self-employed and the averaged

\footnotetext{
10 Including other decisions would require additional limiting assumptions, such as assuming values for decks with which individuals have not yet collected experiences.

11 For example, if a participant has previously chosen five cards each from decks A, B, C, and D, she may have experienced the following past average payoffs per deck: A (10), B (100), C (30), and D (50). If she now selects deck A, the relative disadvantage, RDA, of the selected deck is $90=100(\mathrm{~B})-10(\mathrm{~A})$.
} 
responses. The four items were: What is your level of experience in starting an own a business? What is your level of experience in new product development? What is your level of experience in new market development? What is your level of experience in being self-employed? A Cronbach's alpha of 0.89 indicates high internal reliability. For our analyses, we used entrepreneurial experience as a continuous variable. For illustration purposes, we also split the sample, based on the median (1.5), into more versus less entrepreneurially experienced students. For the non-student sample, a dummy variable indicates the status of the non-student participants as current or past entrepreneurs (one) or as members of the comparison group (zero).

\section{Control variables}

For our analyses, we included various control variables. Entrepreneurial experience is associated with gender and age (Parker, 2004), as is performance on the IGT (e.g., d'Acremont \& Van der Linden, 2006; Van den Bos, Homberg, \& de Visser, 2013; Overman \& Pierce, 2013). We therefore include gender and age as demographic control variables. Age is measured in years, and Gender is represented with an indicator that is set to 1 if the subject is male.

We also included control variables related to the progress of the game. We defined these control variables, first, at the individual level of a single selection for the analyses of the switching likelihood and the relative disadvantage and, second, at the aggregate level of several selections for the analyses of the Concentration of selections, which is assessed per block of 20 decisions. To control for the progress of the game in terms of how many cards were drawn, we included the overall number of the cards that were drawn (Card number $(C N))$ or, for the Concentration of selections, the (ascending) number of the block of decisions. To facilitate readability of the interaction terms (Cohen et al., 2006), we centered these variables such that -1 reflects the first and +1 the last card and block, respectively. In rare cases, due to the specific 
design of the IGT, a deck could run empty prior to the end of the game. Then, a participant was not able to draw a card from that deck anymore. We therefore included three dummies in analyses that indicated whether decks of cards (B, C, D) were empty (A was never depleted). For the analyses of the Concentration of selections, we included the share of decisions in a block that were made after a deck had run empty.

We expect the effects of entrepreneurial experience to depend on the progress of the experiment. At the start, no participant has experienced negative outcomes. Differences in responses to negative experiences will therefore not affect individuals' decision making. The hypothesized effect of entrepreneurial experience on selection behavior, however, will show up later in the game and increase as the experiment proceeds. To account for this time dependency, we also include an interaction between entrepreneurial experience and the progress of the experiment, either in terms of card numbers or decision block numbers.

In the student sample, we also have data on individuals' willingness to take risks (Risk taking), which was measured with a four-item scale (Cronbach's alpha $=0.68)$ from GomezMejia and Balkin (1989) that builds on the work of Gupta and Govindarajan (1984). Entrepreneurs might have different risk attitudes (Baron, 1998, 2004), which may affect performance in the IGT (Upton et al., 2011). We therefore control for risk attitudes in our analyses but do not find a significant effect (see the results section). This is in line with Upton et al. (2011), who generally find only a small effect on the part of risk attitudes on behavior in the IGT.

Table 1 reports summary statistics and pairwise correlation coefficients for all variables at the individual level and for variables varying between individuals. 


\section{RESULTS}

\section{Performance in the IGT: Selecting the 'good' decks, C and D}

We observe clear differences between groups: Subjects with more entrepreneurial experience, regardless of whether they are students or not, are less likely to adjust towards selecting from the 'advantageous' decks, C and D. Specifically, entrepreneurs selected an average of 48.2 cards from decks C and D and 51.8 cards from decks A and B (3.6 fewer 'good' than 'bad' cards, a measure usually referred to as the IGT Net Score; here: -3.6), the matched control group selected 59.8 cards from decks C and D (IGT Net Score $=+19.6$ ), entrepreneurially experienced students selected 52.7 'good' cards on average (IGT Net Score = +5.4 ), and students without entrepreneurial experience selected 57.2 cards on average from the 'advantageous' decks, C and D (IGT Net Score $=+14.4$ ). Due to the direct relationship between payoffs and deck selections, cumulative payoffs differ accordingly between groups. On average, students with less entrepreneurial experience (based on a median split) earned 6.62 points, and students with more experience lost 227.59 points. Entrepreneurs lost an average of 538.00 points, while individuals in the matched sub-sample earned, on average, 178.33 points. The difference between less and more experienced students is significant $(\mathrm{p}=0.003)$, as is the difference between entrepreneurs and their counterparts $(\mathrm{p}<0.001)$. Overall, the performance differential that we observed was rather substantial.

A direct comparison of deck choices between our study and other studies is complicated by substantial variation across samples and study designs, all of which affect IGT outcomes (Overman \& Pierce, 2013). Despite this, the frequencies of selections from the 'good' decks, C and D, in our study are in line with several previous studies. Lehto and Elorinne (2003), for example, report an average of 56.2 'good' cards, and Petry (2001) reports 59 'good' cards. For 
the entrepreneurs in our sample, we observe a negative IGT Net Score. That is, they selected more 'bad' than 'good' cards, which is in the range of results for VMPFC and amygdala patients (Bechara et al., 1999). Our observation that the students, on average, seem to perform worse than the control group from the general population is consistent with Evans, Kemish, and Thurnbull (2004), who report a negative influence on the part of education on IGT performance. Our observed group difference between entrepreneurs and the comparison group (11.6) is very similar to the difference of (10.5) between, for example, individuals with and without substance disorders (Barry \& Petry, 2008). The difference between entrepreneurially more and less experienced students (4.6), however, is much smaller than in Barry and Petry (2008).

In order to better illustrate how, over the course of the task, the various subsamples performed, Figure 2A plots the relative frequency of selections from 'good' decks C and D for the four groups subjects (students with high vs. low entrepreneurial experience, as well as entrepreneurs and their matched control group) for five blocks of 20 selections each $(1-20,21-$ 40, 41-60, 61-80, and 81-100). A one-way between-subjects ANOVA for the two students' subsamples reveals a significant group effect $(\mathrm{p}<0.001)$ and, within groups, a significant effect on the part of the blocks ( $<<0.001)$, as well as a significant interaction between groups and blocks $(p=0.010)$. Comparing entrepreneurs with the normative group, the group effect is significant $(p<0.001)$, as are that of the blocks $(p<0.001)$ and the interaction of the two $(p<0.001)$. Thus, as supported by the visual inspection of Figure 2A, entrepreneurs and entrepreneurially experienced students differ from their comparison groups, and these differences depend on the progression of the game. The observation that overall, all groups tend to shift towards the advantageous decks indicates that the low performance scores of entrepreneurially experienced individuals are likely to result from exploring all decks for a longer period of time, rather than focusing on the 'wrong' 
decks.

\section{[Insert Figure 2 about here]}

\section{Broad Choice Set vs. Concentration of Choices}

$H 1$ predicted that entrepreneurially experienced individuals would retain a broad choice set rather than concentrate their selections. Figure $2 \mathrm{~B}$ plots the average concentration index (Herfindahl Index, HI) for the student and non-student samples for each of the five blocks of 20 decisions that each individual made. Entrepreneurially experienced individuals in both samples show less concentrated choices than their comparison groups. Models 1 in Tables 2 (for the student sample) and 3 (for the non-student sample) report ordinary least square (OLS) regression analyses with the concentration index per 20-decision block as a dependent variable. The tables report bootstrapped standard errors corrected for the clustering of data within participants.

Overall, over the course of the game, all participants increasingly concentrated their choices. This occurred, in particular and not surprisingly, when one of the decks had run empty.

Entrepreneurially experienced individuals concentrated their choices less than the subjects in the comparison groups. These effects are statistically significant in both samples. $H 1$ is, therefore, supported. The effects are also quite stable over the course of the task. The corresponding interaction terms with the progress of the task are not statistically significant.

\section{[Insert Tables 2 and 3 about here]}

\section{Parallel vs. Sequential 'Trial and Error'}

$H 2$ predicted that entrepreneurially experienced individuals would tend towards parallel rather than sequential trial-and-error learning. In the IGT, parallel learning implies more frequent switching between alternatives. Figure 2D plots the average relative frequency of switching on the part of the groups of participants for the five 20-decision blocks. Entrepreneurially 
experienced individuals switched more often than their comparison groups. The gap between the groups narrows over the course of the game. To explore this switching behavior more thoroughly, we employed logistic regression analyses. Because switching might be more likely when the previously selected deck is perceived as disadvantageous, we included the prior selection's relative disadvantage as an additional control variable. Model 3 in Table 2 and Model 3 in Table 3 report the results. As expected, switching became less likely once one or more decks had been depleted. Also, switching became significantly less likely over the course of the task. In addition, the likelihood of switching increased as the prior selection's RDA rose. That is, participants were more likely to switch away from decks with an inferior cumulative payoff history. In support of $H 2$, entrepreneurially experienced individuals had a statistically significant tendency to switch more often. The differences in the probabilities of switching away from a deck, however, are larger at the beginning of the game (3.5 and 21 percentage points for the student and non-student samples, respectively) and smaller at the end ( 0.8 and 11 percentage points for the student and non-student samples, respectively). ${ }^{12}$

More frequent switching by more entrepreneurially experienced individuals could be a result of less effort being invested into information processing and decision making or of boredom, implying a reduced interest in finding the best deck. Bored participants might switch between decks simply for sensation seeking. In both of these cases, individuals' decision making would be characterized by a more heuristic instead of a deliberate thinking style and,

\footnotetext{
12 We expect that entrepreneurially experienced individuals are more likely to stick to seemingly worse decks (see H3). Given this, we may also expect that less entrepreneurially experienced individuals are more likely to switch to seemingly better decks. Thus, the relatively higher degree to which entrepreneurially more experienced individuals switch is likely to be moderated by the relative disadvantage of the previously selected deck. The difference in the probabilities of switching away from a deck should be larger when switching away from decks that maximize one's expected payoffs and smaller for less advantageous decks. In an additional estimation (available upon request), we included such a moderation effect and, indeed, found that the difference in switching likelihood is especially large when the previous deck was payoff-maximizing based on an individual's past experiences with these decks.
} 
consequently, shorter reaction times, which can serve as indicators of different types of thinking and decision making (Baron \& Ward, 2004; Rubinstein, 2014). Because the software logged the time between decisions, we tested for group differences in reaction times using Poisson regressions, with prior payoff as a control variable. The results (available upon request) indicate that more entrepreneurially experienced participants took relatively more time in making their decisions. ${ }^{13}$ This would suggest that these people engaged in less heuristic, more deliberate decision making (Baron \& Ward, 2004; Rubinstein, 2014). It is thus unlikely that a lack of deliberation is responsible for the differences between entrepreneurially experienced individuals and their comparison groups.

\section{Tolerance for Negative Experiences}

$H 3$ predicted that entrepreneurs have a greater tolerance for negative experience histories, and must experience more negative experiences before they remove an alternative from their choice set. Figure $2 \mathrm{C}$ plots the average relative disadvantage (RDA) of the selected deck for the four groups and five time blocks. Entrepreneurially experienced individuals scored higher than the less experienced individuals. To more thoroughly analyze these differences, Model 2 in Table 2 and Model 2 in Table 3 report results of related OLS regression analyses. Estimations indicate that individuals became less likely to accept a relative disadvantage for a selected deck once deck B or D was depleted. These decks are more difficult to judge because they feature a low frequency of relatively larger losses, which creates more need for the exploration of these decks. Thus, exploration is less attractive once these decks, which are more difficult to judge, are empty.

13 Based on the raw data, we observe 4.10 seconds for students with little entrepreneurial experience, 4.93 seconds for students with high levels of entrepreneurial experience, and 6.32 seconds for entrepreneurs. For the matched control group, these data are not available. 
Regarding our key model variables and in support of $H 3$, we find that entrepreneurially experienced individuals (in both the student and the non-student samples) are more likely than their comparison groups to select alternatives that did not maximize expected future payoffs. They select alternatives that on average deviate more strongly from the payoff-maximizing alternative. The models estimate the average disadvantage of a deck that is selected as compared to other decks based on an individual's past experiences gained in the prior selections. For the student sample, more entrepreneurially experienced students accepted deviations (disadvantages) that were, on average, 9 points larger than deviations accepted by less experienced students. Among the non-student sample, entrepreneurs accepted deviations (disadvantages) that were 23 points larger than the deviations accepted by their comparison group. On average, across the course of the game, the advantageous and disadvantageous decks differed in terms of payoffs by 25 points per decision. The observed accepted deviations are thus comparatively large.

The explanatory power of the overall model, in terms of R-squared, however, is relatively low. We attribute this to biases in the OLS model that result from the fact that about $40 \%$ of all responses maximized payoffs. Hence, for $40 \%$ of the responses, the value for the relative disadvantage of the selected deck is equal to the lower bound (zero). This creates a highly skewed distribution. In order to account for these biases, we estimated Tobit models with a lower limit of zero. The results (available upon request) show that the effect sizes, that is, the differences between more and less entrepreneurially experienced individuals, in both samples are larger than in the OLS regressions. For the student sample, the difference is 14 points (more than 50 percent larger), and for the non-student sample, the difference is 28 points (more than 20 percent larger). This provides further support for $H 3$. Our results are also robust when we run logistic regressions with a dependent variable that indicates whether or not a participant deviated 
from the maximum past average payoff (analyses available upon request).

\section{DISCUSSION}

\section{Summary and comparison with clinical research}

The analyses of both the student and the non-student samples reveal a clear pattern: more entrepreneurially experienced individuals display inferior performance on the IGT as compared to less entrepreneurially experienced individuals. This poor performance record does not come as a surprise. The IGT penalizes the longer exploration of seemingly inferior decks, which may have initially appeared superior). Because we hypothesized that entrepreneurially experienced individuals would display higher levels of exploratory perseverance, we expect them to show a broader exploration of decks, including seemingly inferior decks, which naturally results in lower performance scores on the IGT.

The performance of entrepreneurially experienced individuals, in terms of the frequency of selections from the 'good' decks and the magnitude of final losses, is in a similar range as the typical performance of patients with lesions in the VMPFC and the bilateral amygdala (Bechara et al., 1999), schizophrenic patients (e.g., Shurman et al., 2005), and patients suffering from substance abuse (Barry \& Petry, 2008). Does the behavioral similarity of entrepreneurially experienced people and patients imply that both groups suffer from similar problems? Integrating our findings with insights from neuropsychological studies, on the one hand, and with the literature on entrepreneurial metacognition, on the other hand, suggests that - despite the fact that the IGT-behavior of entrepreneurially experienced individuals mimics that of patients - the underlying mechanism is likely to be a very different one.

Prior neuropsychological studies using the IGT have reported substantial variability in healthy control participants' performances (for an overview, see Dunn et al., 2006). Most IGT 
studies that explicitly provide such information (e.g., Bechara et al., 1999; Lehto \& Elorinne, 2003; Worthy, Hawthorne, \& Otto, 2013) identify a significant sub-group of healthy control participants (e.g., 23\% of controls in Bechara et al., 1999; 7.5\% in Lehto \& Elorinne, 2003) who exhibit impaired performance in the IGT, often similar and sometimes even worse than the performance of the patients (e.g., Bechara et al., 1999; Lehto \& Elorinne, 2003). Although the behavior of these healthy underperformers resembled that of the patients, they differed in terms of the physiological results (i.e., SCR), which reflect emotional reactions. While the patients were virtually unable to generate anticipatory SCRs (and, in the case of some types of lesions, also reactive SCRs), the healthy underperformers generated both anticipatory and reactive SCRs, suggesting a well-functioning somatic system (Bechara et al., 1999; Bechara et al., 2000b). Healthy underperformers, thus, do not differ in terms of experiencing emotions; instead, these individuals seem to be able to override their affect-driven impulses or somatic markers by (deliberately) applying higher cognitive processes (Bechara et al., 2000).

Considering the neuropsychological evidence on the subset of healthy IGT underperformers, our own findings of longer decision times and specific behavioral patterns of entrepreneurially experienced individuals, as well as related research on entrepreneurial cognition (e.g., Haynie et al. 2012; Haynie et al., 2009), we propose that our results are suggestive of entrepreneurs' particular ability to apply higher-order cognitive (meta-cognitive) processes to deliberately override affect-driven impulses. Metacognition has been defined by Schraw and Dennison (1994) as the "ability to reflect upon, understand, and control one's learning” (Schraw \& Dennison, 1994: 460). Scholars have suggested potentially superior metacognition as the basis of the "entrepreneurial mindset" (Haynie et al., 2012; Haynie et al., 2009). Indeed, entrepreneurs have been found to possess a more versatile thinking style in that 
they balance both nonlinear (e.g., intuitive, creative) and linear (e.g., analytic, rational) approaches (Groves, Vance, \& Choi, 2011). Our finding that entrepreneurially experienced individuals take more time to make their decisions, which indicates a more deliberate thinking mode (Baron \& Ward, 2004; Rubinstein, 2014), would support this assertion. Thus, entrepreneurially experienced individuals may not be impaired in terms of the development of affective states. Instead, in order to explore, they may cognitively overcome interfering affective states. Because our study design does not allow for explicitly testing these arguments, we suggest that future research implements the IGT in a way that allows for disentangling the mechanisms that differentiate healthy underperformers from individuals with neurological impairment.

\section{Implications}

This study adds to the literature on entrepreneurs' perseverance by advancing exploratory perseverance in concurrent learning settings as a novel construct that complements existing conceptualizations of perseverance (e.g., Baum \& Locke, 2004; Markman et al., 2005; Holland \& Shepherd, 2013). Our conceptual refinement highlights several important aspects. First, perseverance can be defined at different levels, ranging from a specific action (e.g., continuing to choose one alternative, such as venture operations, over another, such as to exit) to a higher level that relates to specific behaviors that comprise sets of actions (continuing to explore several alternatives such as variants of technological implementation). Second, being perseverant in one way may, depending on the context, preclude perseverance in another way (e.g., exploratory perseverance precluded narrow perseverance in our study). Third, being perseverant in one way (e.g., exploratory perseverance in concurrent learning) may complement another type (e.g., perseverance in sticking to an already founded business, as illustrated by portfolio entrepreneurs). 
By offering such a fine-grained conceptualization, this study opens up a new perspective on the discussion of perseverance in the entrepreneurship literature in general (e.g., Gimeno et al., 1997; Holland \& Shepherd, 2013). It emphasizes the importance of defining the scope of the behavioral pattern in question, which may or may not be repeated when encountering adversity, and suggests the need to consider the potential divergence between different types of perseverance. The differences in scope when defining perseverance also relate to the work of van Gelderen (2012), who proposes a process model of perseverance in entrepreneurial goal-striving where goals may refer to different goal levels. In particular, referring to Elliott and Dweck (1988) and Kaplan and Maehr (2007), he outlines how "framing issues as learning goals rather than as performance goals has been proven to be related to perseverance [...] The difference lies in the role that is ascribed to failure: failure makes it more difficult to reach a performance goal, but can in fact enhance learning (Cope \& Watts, 2000; Sitkin, 1992)." Our results lend tentative empirical support to the idea that entrepreneurs may indeed differ in regard to such framing issues.

Future research may also find it worthwhile to go beyond the types of perseverance considered in this study and investigate other conceptualizations of perseverance. Scholars might relax the boundary conditions that we established here in order to focus on exploratory perseverance (such as a lack of switching costs and an exogenously given set of alternatives). As a result, an even more fine-grained distinction between different types of perseverance would be possible. Such a comprehensive conceptual investigation of the construct might allow researchers to address a variety of questions, such as whether or not different types of perseverance are predominantly associated with specific phases of the entrepreneurial processes (e.g., Choi \& Shepherd, 2004) or with distinct behavioral foci (e.g., Brocker et al., 2004). There 
might also be triggers that switch an entrepreneur's thinking from exploratory perseverance to persisting in execution.

The proposed conceptualization of perseverance allowed us to identify the penchant for exploration that entrepreneurs are noted for as a possible reason for their perseverance. Prior studies have established a heightened level of perceived capacity to control adversity (e.g., Markman et al., 2005) as a potential driver of persisting with an activity despite negative experiences - a feature that the task setting in this study explicitly excluded. Another possible reason for entrepreneurs' superior perseverance might lie in a pronounced susceptibility to status-quo bias - a tendency to opt for a previously chosen alternative disproportionately often - (cf., Shepherd et al., 2015) independent of learning opportunities and of control perceptions. Perseverance driven by status-quo bias would be reflected in the task setting employed in this study as narrow perseverance. Based on arguments from real options theory, it has also been suggested — although not empirically supported — that entrepreneurs shy away from an irreversible exit decision because they are more likely to value learning opportunities (Sandri et al., 2010). Building a conceptualization of entrepreneurial perseverance around the setting of an irreversible exit decision, however, blurs the distinction between exploration and exploitation motives because the irreversible decision implies both an end to exploration and a denial of any future exploitation of that opportunity. By drawing attention to settings without irreversible choices, we were able to focus on exploratory rather than exploitative motives. Such settings are not only methodologically interesting but also practically relevant. Entrepreneurs face many decisions in which perseverance may matter but which are not characterized by irreversibility: for example, choices about the width of a product or technology portfolio or choices with respect 
to partners in teams, where the decision to take on one partner does not necessarily exclude another.

We also contribute to research on entrepreneurial learning (e.g., Corbett, 2007) by connecting it to the discussion of entrepreneurial perseverance. Parker (2006) concludes that entrepreneurs are comparatively slow to update their expectations in light of new information (Parker, 2006) and, therefore, tend to be more perseverant. We suggest that entrepreneurs might deliberately seek more evidence before ultimately deciding on the value of an alternative and eventually removing it from their choice set. Thus, their perseverance might not result from a learning weakness but from higher aspirations with respect to the learning outcome.

Furthermore, as discussed above, our interpretation suggests that rather than simply being 'blind' or less averse to losses, entrepreneurs' perseverance may result from deliberately accepting losses and accompanying negative emotions as part of their learning. Resistance to automatic behavioral reactions to aversive emotions requires a comparatively strong meta-cognitive ability. Our study suggests a specific part of metacognitive ability that might be especially relevant, that is, the ability to deliberately suppress affect-driven reactions to negative experiences (e.g., Hayward et al., 2010; Shepherd et al., 2011). Such meta-cognitive ability might make entrepreneurs less susceptible to the 'hot stove' effect (Denrell \& March, 2001), which leads individuals to erroneously under-sample information about options that have initially yielded negative results.

This study also has a practical implication. The peculiarities of entrepreneurial decision making and learning, as well as their consequences, must be taken into account when designing policy interventions, entrepreneurship programs, and corporate activities that aim to create an 'entrepreneurial mindset'. By experiencing the IGT as part of their training (e.g., Waters-Wood 
et al., 2012), entrepreneurs could be alerted to their tendency towards exploratory perseverance — and its ambiguous performance implications. It is important to note that the concept of exploratory perseverance can be applied beyond explaining a delayed exit from entrepreneurship. It also applies to the management of broad product or technology portfolios, where entrepreneurs seem to require stronger signals of inferiority than others in order to remove an option from their portfolios. While the reduced susceptibility to the 'hot stove' effect may result in less biased sampling and ultimately superior outcomes (Denrell \& March, 2001), the weak performance in the IGT illustrates that exploratory perseverance does not necessarily translate into superior performance in all contexts.

The results also have implications for the relationship between venture capitalists and entrepreneurs (e.g., Busenitz, Fiet, \& Moesel, 2004). Anecdotal evidence suggests that disagreement over how long and how extensively entrepreneurs should explore alternatives is a frequent source of conflict in this relationship. As an inherent feature of entrepreneurs' decision making and learning, venture capitalists should be careful not to stymie exploratory perseverance by strictly imposing financially driven milestones. Entrepreneurs, in turn, should carefully assess the boundary conditions of the particular task settings they face in order to gauge whether they should put the brakes on their exploratory perseverance.

\section{Limitations and opportunities for future research}

Several limitations of our study must be accounted for in future research. The first and foremost limitation is related to causality and rests on using cross-sectional data. While the IGT has the advantage of being an extensively validated clinical measure (Bechara \& Damasio, 2005; Dunn et al., 2006), it remains a quasi-experimental setup (Grant \& Wall, 2009). Because we are not able to randomly manipulate entrepreneurial experience, we cannot clearly determine 
whether people who showed a specific behavior on the IGT were more likely to have gained entrepreneurial experience or whether their entrepreneurial experience caused that specific behavior in the IGT.

A further limitation results from using an abstract and laboratory-like setting. On the one hand, the level of abstraction ensures that behavior of participants is unlikely to be confounded by related experiences in the field. This is important because these experiences would, by definition, differ between more and less entrepreneurially experienced participants. Thereby, the design increases internal validity and reduces threats from endogeneity biases. Experiments, however, are often challenged based on their limited external validity and generalizability, especially with regard to sample size and sample composition. Although the size of our nonstudent sample, including real entrepreneurs, is similar to other sample sizes reported in the entrepreneurship literature (e.g., Gatewood et al., 2002; Sandri et al., 2010), we acknowledge that there could be unobserved variables correlated with the variables of interest, confounding our findings in the non-student sample. Furthermore, we do not have much information on the individuals in the normative sample, especially regarding their entrepreneurial experience. The normative sample is drawn from the general population, which is characterized by a relatively low percentage of entrepreneurs. We, therefore, believe that it is safe to assume that the entrepreneurs subsample is characterized by significantly higher levels of entrepreneurial experience than the subsample matched from the normative sample. The larger student sample, which is split solely based on self-reported entrepreneurial experience, provides a setting that is less susceptible to such challenges.

Having both a rather large and homogeneous student sample and a smaller, more heterogeneous sample of entrepreneurs with a matched control group enables us to draw more 
robust conclusions. A valuable way to continue this research would be to expand the range of entrepreneurial sub-populations included in the sample in future larger-scale studies and collect more extensive background information on participants. Collecting data from different types of entrepreneurs (e.g., novice, serial, portfolio; successful vs. unsuccessful) at different stages of their professional tenure and including detailed background information on participants (e.g., personality traits and profiles; cf. Rauch \& Frese, 2007) would probably allow scholars to even more closely link the behavioral patterns observed in the lab to 'real-life' implications. Given the specific design of the IGT, with its exploration of multiple options, portfolio entrepreneurs, with their engagement in multiple businesses, are an especially interesting population.

Another set of limitation relates to the specific design of the IGT. The design has been developed to identify perseverance in behavior that initially appears superior but, over time, reveals its inferiority (for example, keep selecting from decks A and B). ${ }^{14}$ While the design of the IGT deviates from entrepreneurial settings in several respects, it is precisely these deviations that enable us to identify the exploratory motive behind entrepreneurs' perseverance by excluding other possibly confounding motives. Sunk costs and switching costs, including irreversible decisions, are often elements of entrepreneurial contexts. Including them into our experiment, however, would have introduced an additional confounding factor, hampering the clear identification of exploration-motivated perseverance. Furthermore, entrepreneurial settings are often characterized by opportunities that are either created by or at least influenced by an entrepreneur's capabilities; that is, the outcome at least partially depends on an entrepreneur's capabilities (Sarasvathy, 2001, 2008; Alvarez \& Barney, 2007). Our research design deliberately

14 The alternatives offered in the IGT are admittedly rather limited (Bechara et al., 1994). There are efforts to modify the standardized version of the IGT by extending its alternatives (e.g., Chiu \& Lin, 2007; Horstmann et al., 2012; Tom et al., 2007). Such efforts could improve our understanding of the precise features of a set of options that appeals to entrepreneurs - and, possibly, to which types of entrepreneurs these options appeal. 
focuses on alternatives with externally determined outcomes. Thereby, we can differentiate the exploratory motive of perseverance from an effectuating motive, where people persevere because they believe that they, more so than others, can turn a seemingly inferior alternative into a good one. Both these limitations imply that our results positively identify exploratory perseverance as a typical behavior of entrepreneurs. This behavior, however, may act in concert with or could be leveraged or perhaps mitigated by other mechanisms that might also trigger perseverance, depending on the specific context.

Future studies are likely to benefit from being very precise in regard to what elements of their research design could be responsible for perseverance. We suggest that at least three elements should be differentiated: switching costs (including irreversible decisions reflected by infinite switching cost), endogenous outcomes, and feedback about hidden qualities of the behavioral alternatives. Studies that combine all these characteristics would offer a context that more closely reflects real-life entrepreneurial settings. In doing so, they allow for further insights into the relative importance of the various motives that underlie entrepreneurs' perseverance, ranging from exploration to psychological inertia, such as the status-quo bias, and to overoptimistic beliefs in one's ability to "make it work". At the same time, such a combination of features also creates difficulties in disentangling the various reasons for entrepreneurial perseverance. Scientific progress on this topic is, therefore, likely to rest on the triangulation of studies of different types. 


\section{REFERENCES}

d'Acremont, M., Van der Linden, M. 2006. Gender differences in two decision-making tasks in a community sample of adolescents. International Journal of Behavioral Development, 30 , $352-358$.

Adner, R., Levinthal, D.A. 2004. What is not a real option: Considering boundaries for the application of real options to business strategy. Academy of Management Review, 29, 74-85.

Alvarez, S.A., Busenitz, L.W., 2001. The entrepreneurship of resource-based theory. Journal of Management, 27(6), 755-776.

Alvarez, S.A., Barney, J.B. 2007. Discovery and creation: Alternative theories of entrepreneurial action. Strategic Entrepreneurship Journal, 1(1-2), 11-26.

Baron, R. 1998. Cognitive mechanisms in entrepreneurship: why and when entrepreneurs think differently than other people. Journal of Business Venturing, 13, 275-294.

Baron, R. 2004. The cognitive perspective: A valuable tool for answering entrepreneurship's basic "why" questions. Journal of Business Venturing, 19, 221-239.

Baron, R. 2008. The role of affect in the entrepreneurial process. Academy of Management Review, 33, 328-340.

Baron, R., Ensley, M. 2006. Opportunity recognition as the detection of meaningful patterns: Evidence from comparisons of novice and experienced entrepreneurs. Management Science, $52,1331-1344$.

Baron, R.A., Hmieleski, K.M., Henry, R.A. 2012. Entrepreneurs' dispositional positive affect: the potential benefits - and potential costs — of being "up". Journal of Business Venturing, 27, 310-324.

Baron, R.A., Tang, J., Hmieleski, K.M. 2011. The downside of being 'up': Entrepreneurs' dispositional positive affect and firm performance. Strategic Entrepreneurship Journal, 5, 101-119.

Baron, R.A., Ward, T. 2004. Expanding entrepreneurial cognition's toolbox: Potential contributions from the fields of cognitive science. Entrepreneurship Theory \& Practice, 28, $553-573$.

Barry, D., Petry, N.M. 2008. Predictors of decision-making on the Iowa Gambling Task: independent effects of lifetime history of substance use disorders and performance on the Trail Making Test. Brain and Cognition, 66, 243-252.

Baum, J.R., Locke, E.A. 2004. The relationship of entrepreneurial traits, skill, and motivation to subsequent venture growth. Journal of Applied Psychology, 89(4), 587-598.

Bechara A 2007. Iowa Gambling Task Professional Manual. Psychological Assessment Resources, Inc., Lutz (FL).

Bechara, A., Damasio, A.R. 2005. The somatic marker hypothesis: A neural theory of economic decision. Games and Economic Behavior, 52, 336-372.

Bechara, A., Damasio, A.R., Damasio, H., Anderson, S.W. 1994. Insensitivity to future consequences following damage to human prefrontal cortex. Cognition, 50, 7-15.

Bechara, A., Damasio, H., Damasio, A.R., Lee, G.P. 1999. Different contributions of the human amygdala and ventromedial prefrontal cortex to decision-making. Journal of Neuroscience, $19,5473-5481$.

Bechara, A., Damasio, H., Tranel, D., Damasio, A.R. 1997. Deciding advantageously before knowing the advantageous strategy. Science, 275(5304), 1293-1295.

Bechara, A., Damasio, H., Damasio, A.R., 2000b. Emotion, decision-making and the orbifrontal 
cortex. Cerebral Cortex, 10: 295-307.

Bechara, A., Tranel, D., Damasio, H., 2000a. Characterization of the decision-making deficit of patients with ventromedial prefrontal cortex lesions. Brain, 123, 2189-2202.

Bechara, A., Tranel, D., Damasio, H., Damasio, A.R. 1996. Failure to respond autonomically to anticipated future outcomes following damage to prefrontal cortex. Cerebral Cortex, 6(2), 215-225.

Bibby, P. A., Ferguson, E. 2011. The ability to process emotional information predicts loss aversion. Personality and Individual Differences, 51(3), 263-266.

Bönte, W., Procher, V., \& Urbig, D., in press. Biology and selection into entrepreneurship: The relevance of prenatal testosterone exposure. Entrepreneurship, Theory \& Practice.

Brockner, J., Higgins, E.T. 2001. Regulatory focus theory: implications for the study of emotions at work. Organizational Behavior and Human Decision Processes, 86, 35-66.

Brockner, J., Higgins, E.T., Low, M.B. 2004. Regulatory focus theory and the entrepreneurial process. Journal of Business Venturing, 19, 203-220.

Bryant, P., 2007. Self-regulation and decision heuristics in entrepreneurial opportunity evaluation and exploitation. Management Decision, 45, 732-748.

Burmeister, K., Schade, C. 2007. Are entrepreneurs' decisions more biased? An experimental investigation of the susceptibility to status quo bias. Journal of Business Venturing, 22, 340-362.

Busenitz, L.W. 1996. Research on entrepreneurial alertness: Sampling, measurement, and theoretical issues. Journal of Small Business Management, 34(4), 35-44.

Busenitz, L.W., Barney, J.B. 1997. Differences between entrepreneurs and managers in large organizations: biases and heuristics in strategic decision-making. Journal of Business Venturing, 12, 9-30.

Busenitz, L.W., Fiet, J.O., Moesel, D.D. 2004. Reconsidering the venture capitalists" "value added" proposition: An interorganizational learning perspective. Journal of Business Venturing, 19, 787-807.

Cardon, M.S., Wincent, J., Singh, J., Drnovsek, M. 2009. The nature and experience of entrepreneurial passion. Academy of Management Review, 34, 511-532.

Carver, C.S., Scheier, M.F. 1998. On the Self-Regulation of Behavior. Cambridge University Press, New York, NY.

Carver, C.S., Scheier, M.F. 2001. Optimism, pessimism, and self-regulation. In Chang, E.C. (ed.). Optimism and Pessimism. American Psychological Association: Washington (DC), pp. 31-51.

Chandler, G.N, DeTienne, D.R., McKelvie, A., Mumford, T.V. 2011. Causation and effectuation processes: A validation study. Journal of Business Venturing, 26, 375-390.

Chiu Y.-C., Lin, C.H. 2007. Is deck C an advantageous deck in the Iowa Gambling Task? Behavioral and Brain Functions, 3, 37.

Cooper, A.C., Folta, T.B., Woo, C. 1995. Entrepreneurial Information Search. Journal of Business Venturing. 10, 107-120.

Corbett, A.C. 2007. Learning asymmetries and the discovery of entrepreneurial opportunities. Journal of Business Venturing, 22, 97-118.

Crossan, M.M., Lane, H.W., White, R. E. 1999. An organizational learning framework: from intuition to institution. Academy Management Review, 24, 522-537.

Davies, S. 1979. Choosing between Concentration Indices: The Iso-concentration curve. Economica, 46(181), 67-75

Denrell, J., March, J.G. 2001. Adaptation as information restriction: the hot stove effect. 
Organization Science, 12, 523-538.

DeTienne, D.R., Shepherd, D.A., De Castro, J.O. 2008. The fallacy of "only the strong survive": The effects of extrinsic motivation on the persistence decisions for under-performing firms. Journal of Business Venturing, 23, 528-546.

Drucker, P.F., 1998. The discipline of innovation. Harvard Business Review, 76(6), 149-157.

Dunn, B.D., Dalgleish, T., Lawrence, A.D. 2006. The somatic marker hypothesis: A critical evaluation. Neuroscience and Biobehavioral Reviews, 30, 239-271.

Eich, E. 1995. Searching for mood dependent memory. Psychological Science, 6, 67-75.

Elston, J.A., Audretsch, D.B. 2011. Financing the entrepreneurial decision: An empirical approach using experimental data on risk. Small Business Economics, 36, 209-222.

Evans, C.E., Kemish, K., Turnbull, O.H. 2004. Paradoxical effects of education on the Iowa Gambling Task. Brain and Cognition, 54(3), 240-244.

Fiet, J.O. 2007. A prescriptive analysis of search and discovery. Journal of Management Studies, 44, 592-611.

Forbes, D. P. 2005. Are some entrepreneurs more overconfident than others? Journal of Business Venturing, 20, 623-640.

Forgas, J.P. 1995. Mood and judgment: The affect infusion model (AIM). Psychological Bulletin, 117(1): 39-66.

Franken, I.H.A., Muris, P. 2005. Individual differences in decision-making. Personality Individual Differences, 39, 991-998.

Fredrickson, B.L. 2001. The role of positive emotions in positive psychology: the broaden-andbuild theory of positive emotions. American Psychologist, 56, 218-226.

Fredrickson, B.L., Branigan, C.A., 2005. Positive emotions broaden the scope of attention nd thought-action repertoires. Cognition and Emotion, 19, 313-332.

Forgas, J.P., Baumeister, R.F., Tice, D.N., 2009. The Psychology of Self-Regulation. Psychology Press Limited, Sydney.

Gaglio C.M. 2004. The role of mental simulations and counterfactual thinking in the opportunity identification process. Entrepreneurship Theory \& Practice, 28(6), 533-552.

Gaglio, C.M., Katz, J., 2001. The psychological basis of opportunity identification: Entrepreneurial alertness. Journal of Small Business Economics, 16, 11-95.

Gatewood, E.J., Shaver, K.G., Powers, J.B., Gartner, W.B. 2002. Entrepreneurial expectancy, task effort, and performance. Entrepreneurship Theory \& Practice, 26, 187-206.

Gimeno, J., Folta, T.B., Cooper, A.C., Woo, C.Y. 1997. Survival of the fittest? Entrepreneurial human capital and the persistence of underperforming firms. Administrative Science Quarterly, 42, 750-783.

Gomez-Mejia, L.R., Balkin, D.B. 1989. Effectiveness of individual and aggregate compensation strategies. Industrial Relations, 28, 431-445.

Grant, A. M., Wall, T. D. 2009. The neglected science and art of quasi-experimentation. Whyto, when-to, and how-to advice for organizational researchers. Organizational Research Methods, 12(4), 653-686.

Grégoire, D.A., Corbett, A.C., McMullen, J.S. 2011. The cognitive perspective in entrepreneurship: An agenda for future research. Journal of Management Studies, 48, $1443-1477$.

Gruber, M., MacMillan, I.C., Thompson, J.D. 2008. Look before you leap: Market opportunity identification in emerging technology firms. Management Science, 54, 1652-1665.

Gupta, A.K., Govindarajan, V. 1984. Business unit strategy, managerial characteristics, and business unit effectiveness at strategy implementation. Academy of Management Journal, 
$27,25-41$.

Gupta, A.K., Smith, K.G., Shalley, C.E. 2006. The interplay between exploration and exploitation. Academy of Management Journal, 49: 693-706.

Halamish, V., Liberman, N., Higgins, E.T., Idson, L.C. 2008. Regulatory focus effects on discounting over uncertainty for losses vs. gains. Journal of Economic Psychology, 29, 654-666.

Harman, J.L., 2011. Individual differences in need for cognition and decision making in the Iowa Gambling task. Personality and Individual Differences, 51, 112-116.

Harrison, G., Lau, M., Williams, M.B. 2002. Estimating individual discount rates in Denmark: a field experiment. American Economic Review, 92, 1606-1617.

Haynie, J.M., Shepherd, D.A., Mosakowski, E., Earley, P.C. 2010. A situated metacognitive model of the entrepreneurial mindset. Journal of Business Venturing, 25(2), 217-229.

Haynie, J.M., Shepherd, D.A., Patzelt, H. 2012. Cognitive adaptability and an entrepreneurial task: The role of metacognitive ability and feedback. Entrepreneurship Theory \& Practice, $36,237-265$.

Hayton, J.C., Cholakova, M. 2012. The role of affect in the creation and intentional pursuit of entrepreneurial ideas. Entrepreneurship Theory \& Practice, 26, 41-68.

Hayward, M.L., Forster, W.R., Sarasvathy, S.D., Frederickson, B.L. 2010. Beyond hubris: How highly confident entrepreneurs rebound to venture again. Journal of Business Venturing, 25, 569-282.

Higgins, E.T. 1997. Beyond pleasure and pain. American Psychologist, 52, 1280-1300.

Higgins, E.T. 1998. Promotion and prevention: regulatory focus as a motivational principle. In Zanna M.P. (ed.). Advances in Experimental Social Psychology, vol. 30. Academic Press: New York (NY), pp. 1-46.

Hitt, M.A., Bierman, L., Shimizu, K., Kochhar, R. 2001. Direct and moderating effects of human capital on strategy and performance in professional service firms: A resource-based perspective. Academy of Management Journal, 44, 13-28

Holland, D.V., Shepherd, D.A. 2013. Deciding to persist: Adversity, values, and entrepreneurs' decision policies. Entrepreneurship Theory \& Practice, 37, 331-358.

Horstmann, A., Villringer, A., Neumann, J. 2012. Iowa Gambling Task: There is more to consider than long-term outcome. Frontiers in Neuroscience, 6(article 61), 1-10.

Keh, H.T., Foo, M.D., Lim, B.C. 2002. Opportunity evaluation under risky conditions: The cognitive processes of entrepreneurs. Entrepreneurship Theory \& Practice, 27, 125-148.

Kim, J.-N., Clelland, I., Bach, S. 2010. Entrepreneurs as parallel processors: an examination of a cognitive model of new venture opportunity evaluation. Academy of Entrepreneurship Journal, 16(2), 57-86.

Koellinger, P., Minniti, M., Schade, C. (2007), "I think I can, I think I can”: Overconfidence and entrepreneurial behavior. Journal of Economic Psychology, 28(4), 502-527.

Krueger, N.F. 2003. The cognitive psychology of entrepreneurship. In Acs, Z.J., Audretsch, D.B. (eds.). Handbook of Entrepreneurship Research: An Interdisciplinary Survey and Introduction, International Handbook Series on Entrepreneurship, Vol. 1. Kluwer Academic Publishers, Boston, MA, pp. 105-140.

Laureiro-Martínez, D., Brusoni, S., Zollo, M. 2010. The neuroscientific foundations of the exploration-exploitation dilemma. Journal of Neuroscience, Psychology, and Economics, 3(2), 95-115.

Laureiro-Martínez, D., Brusoni, S., Canessa, N., Zollo, M. 2014. Understanding the exploration- 
exploitation dilemma: An fMRI study of attention control and decision-making performance. Strategic Management Journal. doi: 10.1002/smj.2221.

Liberman, N., Molden, D.C., Idson, L.C., Higgins, T.E. 2001. Promotion and prevention focus on alternative hypotheses: Implications for attributional functions. Journal of Personality and Social Psychology, 80 (1), 5-18.

Lowe, R,A., \& Ziedonis, A. A. (2006). Overoptimism and the performance of entrepreneurial firms. Management Science, 52(2), 173-186.

Lynn, G. S., Morone, J. G., Paulson, A. S. 1996. Marketing and discontinuous innovation: the probe and learn process. California Management Review, 38(3), 8-37.

Makhija, M. 2003. Comparing the resource-based and market-based views of the firm: empirical evidence from Czech privatization. Strategic Management Journal, 24, 433-451.

March, J.G. 1991. Exploration and exploitation in organizational learning. Organization Science, 2, 71-87.

March, J.G., Simon, H. 1958. Organizations. John Wiley and Sons: New York (NY).

Markman, G.D., Baron, R.A., 2003. Person-entrepreneurship fit: Why some people are more successful as entrepreneurs than others. Human Resource Management Review, 13, 281301.

Markman, G.D., Baron, R.A., Balkin, D.B. 2005. Are perseverance and self-efficacy costless? Assessing entrepreneurs' regretful thinking. Journal of Organizational Behavior 26(1), 1 19.

McGrath, R. G. 2001. Exploratory learning, innovative capacity, and managerial oversight. Academy of Management Journal, 44, 118-131.

McMullen, J.S., Shepherd, D.A. 2002. Regulatory Focus and Entrepreneurial Intention: Action Bias in the Recognition and Evaluation of Opportunities. Frontiers of Entrepreneurship Research. Babson, Wellesley, MA.

McMullen, J.S., Shepherd, D.A. 2006. Entrepreneurial action and the role of uncertainty in the theory of the entrepreneur. Academy of Management Review, 31(1), 132-152.

Miller, C.C. 2008. Decision comprehensiveness and firm performance: Toward a more complete understanding. Journal of Behavioral Decision Making, 21, 598-620.

Overman, W.H., Pierce, A. 2013. Iowa Gambling Task with non-clinical participants: Effects of using real + virtual cards and additional trials. Frontiers in Psychology, 4: 935.

Parker, S. 2004. The Economics of Self-Employment and Entrepreneurship. Cambridge University Press, Cambridge (UK).

Parker, S. 2006. Learning about the unknown: How fast do entrepreneurs adjust their beliefs? Journal of Business Venturing, 21, 1-26.

Patel, P.C., Thatcher, S.M.B. 2012. Sticking it out: Individual attributes and persistence in selfemployment. Journal of Management, DOI 10.1177/0149206312446643.

Petry, N.M. 2001. Substance abuse, pathological gambling, and impulsiveness. Drug and Alcohol Dependence, 63, 29-38.

Pham, M.T., Higgins, E.T. 2005. Promotion and prevention in consumer decision-making: The state of the art and theoretical propositions. In Ratneshwar, S., Mick, D.G. (eds.). Inside Consumption: Consumer Motives, Goals, and Desires. Routledge, New York, NY.

Pham, M.T., Chang, H.H. 2010. Regulatory focus, regulatory fit, and the search and consideration of choice alternatives. Journal of Consumer Research, 37, 626-640.

Rauch, A., \& Frese, M. (2007). Let's put the person back into entrepreneurship research: A metaanalysis on the relationship between business owners' personality traits, business creation, 
and success. European Journal of Work \& Organizational Psychology, 16, 353-385.

Rowe, G., Hirsh, J.B., Anderson, A.J. 2007. Positive affect increases the breadth of attentional selection. Proceedings of the National Academy of Sciences, 104, 383-388.

Rubinstein, A., 2014. A typology of players: between instinctive and contemplative. Tel Aviv: Mimeo.

Sandri, S., Schade, C., Mußhoff, O., Odening, M. 2010. Holding on for too long? An experimental study on inertia in entrepreneurs' and non-entrepreneurs' disinvestment choices. Journal of Economic Behavior \& Organization, 76, 30-44.

Sarasvathy, S., 2001. Causation and effectuation: Toward a theoretical shift from economic inevitability to entrepreneurial contingency. Academy of Management Review, 26(2), 243263.

Sarasvathy, S., 2008. Effectuation: Elements of Entrepreneurial Expertise. Edward Elgar Publishing Limited, Cheltenham, UK.

Schumpeter, J.A. 1934. The Theory of Economic Development: An Inquiry Into Profits, Capital, Credit, Interest, and the Business Cycle. Harvard University Press, Cambridge (MA).

Shane, S., Locke, E.A., Collins, C.J. 2003. Entrepreneurial motivation. Human Resource Management Review, 13(2), 257-279.

Shane, S., Venkataraman, S., 2000. The promise of entrepreneurship as a field of research. Academy of Management Review, 25, 217-226.

Shepherd, D.A., Zacharakis, A., Baron, R.A. 2003. VC's decision processes: evidence suggesting more experience may not always be better. Journal of Business Venturing, 18, $381-401$.

Shepherd, D.A., Wiklund, J., Haynie, J.M. 2009. Moving forward: Balancing the financial and emotional costs of business failure. Journal of Business Venturing, 24, 134-148.

Shepherd, D.A., Patzelt, H., Wolfe, M. 2011. Moving forward from project failure: negative emotions, affective commitment, and learning form the experience. Academy of Management Journal, 54, 1229-1259.

Shepherd, D.A., Williams, T.A., Patzelt, H. 2015. Thinking about entrepreneurial decision making: Review and research agenda. Journal of Management, 41(1), 11-46.

Shurman, B., Horan, W.P., Nuechterlein, K.H. 2005. Schizophrenia patients demonstrate a distinctive pattern of decision-making impairment on the Iowa Gambling Task. Schizophrenia Research, 72(2), 215-224.

Simon, M., Houghton, S. M., Aquino, K. 2000. Cognitive biases, risk perception, and venture formation: How individuals decide to start companies. Journal of Business Venturing, 15, 113-134.

Starmer, C., Sugden, R. 1991. Does the random-lottery incentive system elicit true preferences? An experimental investigation. American Economic Review, 81, 971-978.

Stoltz, P. G. (1997). Adversity quotient: Turning obstacles into opportunities. Wiley: New York. Tom, S.M., Fox, C.R., Trepel, C., Poldrack, R.A. 2007. The neural basis of loss aversion in deceision-making under risk. Science, 315(January), 515-518. CHECK

Toplak, M. E., Sorge, G. B., Benoit, A., West, R. F., \& Stanovich, K. E., 2010. Decision-making and cognitive abilities: A review of associations between Iowa Gambling Task performance, executive functions, and intelligence. Clinical Psychology Review, 30(5), 562581.

Ucbasaran, D., Westhead, P., Wright, M., Flores, M. 2010. The nature of entrepreneurial experience, business failure, and comparative optimism. Journal of Business Venturing, 25, 
541-555.

Upton, D.J., Bishara, A.J., Ahn, W.-Y., Stout, J.C. 2011. Propensity for risk taking and trait impulsivity in the Iowa Gambling Task. Personality and Individual Differences, 50, 492495.

Urbig, D., Weitzel, U., Rosenkranz, S., van Witteloostuijn, A. 2012. Exploiting opportunities at all cost? Entrepreneurial intent and externalities. Journal of Economic Psychology, 33(2), 379-93.

Van Gelderen, M. 2012. Perseverance strategies for enterprising individuals. International Journal of Entrepreneurial Behavior and Research, 18(6), 630-648.

Van den Bos, R., Homberg, J., de Visser, L. 2013. A critical review of sex differences in decision-making tasks: Focus on the Iowa Gambling Task. Behavioural Brain Research, 238, 95-108.

Verheul, I., Thurik, R., Grilo, I., Van Der Zwan, P. 2012. Explaining preferences and actual involvement in self-employment: Gender and the entrepreneurial personality. Journal of Economics Psychology, 33: 325-341.

Wang, C.L. 2008. Entrepreneurial orientation, learning orientation, and firm performance. Entrepreneurship Theory \& Practice, 32, 635-657.

Waters-Wood, S.M., Xiao, L., Denburg, N.L., Hernandez, M., Bechara, A. 2012. Failure to learn from repeated mistakes: persistent decision-making impairment as measured by the iowa gambling task in patients with ventromedial prefrontal cortex lesions. Journal of the International Neuropsychological Society, 18(05), 927-930.

Weitzel, U., Urbig, D., Desai, S., Sanders, M., Acs, Z. 2010. The good, the bad, and the talented: Entrepreneurial talent and selfish behavior. Journal of Economic Behavior \& Organization, 76(1), 64-81.

Westhead, P., Wright, W. 1998. Novice, portfolio and serial founders: Are they different? Journal of Business Venturing, 13, 173-204.

Worthy, D.A., Hawthorne, M.J., Otto, A.R. 2013. Heterogeneity of strategy use in the Iowa gambling task: a comparison of win-stay/lose-shift and reinforcement learning models. Psychonomic Bulletin \& Review, 20(2), 364-371.

Wu, B., Knott, A.M., 2006, Entrepreneurial risk and market entry. Management Science, 52 (9), 1315-1330.

Zhao, H., Seibert, S.E., Hills, G. 2005. The mediating role of self-efficacy in the development of entrepreneurial intentions. Journal of Applied Psychology, 90, 1265-1272. 
TABLE 1:

SUMMARY STATISTICS AND CORRELATION TABLE

\begin{tabular}{|c|c|c|c|c|c|c|c|c|c|c|c|c|c|c|c|c|}
\hline Sample size & \multicolumn{4}{|c|}{ Summary statistics } & \multicolumn{12}{|c|}{ Binary correlations at the individual level } \\
\hline Dependent Variables & Mean & S.D. & Mean & S.D. & 1 & 2 & 3 & 4 & 5 & 6 & 7 & 8 & 9 & 10 & 11 & 12 \\
\hline 2 Concentration in selection & -1.00 & 0.23 & -0.94 & 0.28 & $-.51^{* * *}$ & & $-.86^{* * *}$ & $.59^{* * *}$ & -.00 & -.10 & & .04 & $.24^{*}$ & $.49^{* * *}$ & & $-.37^{* * *}$ \\
\hline 3 Switching likelihood & 0.53 & 0.24 & 0.49 & 0.28 & $.44^{* * * *}$ & $-.83^{* * *}$ & & $-.52^{* * *}$ & -.06 & .11 & & -.11 & -.16 & $-.39^{* * *}$ & & $.29^{* *}$ \\
\hline 4 Selection of deck C or D & 0.55 & 0.12 & 0.57 & 0.15 & $-.74^{* * *}$ & $.56^{* * *}$ & $-.46^{* * *}$ & $\cdot$ & $-.17^{+}$ & -.08 & & $-.28^{* *}$ & $.25^{*}$ & $.46^{* * *}$ & & $-.33^{* * *}$ \\
\hline \multicolumn{17}{|l|}{ Demographic control variables } \\
\hline 7 Risk taking & 2.83 & 0.69 & & & .02 & .01 & .01 & .07 & -.03 & $.09^{+}$ & $\bullet$ & & & & & \\
\hline \multicolumn{17}{|l|}{ Game control variables } \\
\hline 8 Empty deck B & 0.02 & 0.07 & 0.01 & 0.04 & $.33^{* * *}$ & .06 & .01 & $-.46^{* * *}$ & .02 & -.01 & -.03 & & -.03 & -.04 & & $.30^{* *}$ \\
\hline 9 Empty deck C & 0.03 & 0.08 & 0.00 & 0.03 & $-.23^{* * *}$ & $.47^{* * *}$ & $-.36^{* * *}$ & $.42^{* * *}$ & -.07 & -.03 & .04 & $-.11^{*}$ & & -.06 & & -.04 \\
\hline 10 Empty deck D & 0.04 & 0.10 & 0.02 & 0.06 & $-.39^{* * *}$ & $.53^{* * *}$ & $-.40^{* * *}$ & $.46^{* * *}$ & -.03 & .02 & .03 & $-.15^{* *}$ & -.06 & $\cdot$ & & .02 \\
\hline \multicolumn{17}{|l|}{ Entrepreneurial experience } \\
\hline
\end{tabular}

Notes: Summary and correlation statistics are reported at the individual level; decision-level variables are averaged at the individual level.

Only variables that vary between individuals are reported. The lower left triangle in the correlation table is based on the student sample; the upper right triangle is based on entrepreneurs and their matched counterparts from the normative sample. Pearson correlations are reported. 
TABLE 2:

REGRESSION ANALYSES FOR STUDENT SAMPLE

\begin{tabular}{|c|c|c|c|c|c|c|}
\hline \multirow{3}{*}{$\begin{array}{l}\text { Model } \\
\text { Dependent Variable } \\
\text { Constant }\end{array}$} & \multirow{2}{*}{\multicolumn{2}{|c|}{$\begin{array}{c}\mathbf{1} \\
\text { Concentration of } \\
\text { selections }(H I)\end{array}$}} & \multirow{2}{*}{\multicolumn{2}{|c|}{$\begin{array}{c}\mathbf{2} \\
\text { Relative disadvantage of } \\
\text { selected deck }(R D A)\end{array}$}} & \multicolumn{2}{|r|}{3} \\
\hline & & & & & Switchin & $\begin{array}{l}\text { likelihood } \\
W)\end{array}$ \\
\hline & -0.93 & $(0.06) * * *$ & 28.56 & $(3.59) * * *$ & 0.21 & $(0.34)$ \\
\hline $\begin{array}{l}\text { Age } \\
\text { Gender (female) }\end{array}$ & $\begin{array}{l}-0.00 \\
-0.04\end{array}$ & $\begin{array}{l}(0.00) \\
(0.02)+\end{array}$ & $\begin{array}{r}0.04 \\
-0.55\end{array}$ & $\begin{array}{l}(0.14) \\
(1.10)\end{array}$ & $\begin{array}{r}-0.01 \\
0.12\end{array}$ & $\begin{array}{l}(0.01) \\
(0.10)\end{array}$ \\
\hline $\begin{array}{l}\text { Personality control variables } \\
\text { Risk taking } \\
\text { Game control variables }\end{array}$ & 0.00 & $(0.01)$ & 0.41 & $(0.49)$ & 0.03 & $(0.05)$ \\
\hline Empty deck B (frequency over block) & 0.08 & $(0.04)+$ & & & & \\
\hline $\begin{array}{l}\text { Empty deck B (dummy) } \\
\text { Empty deck C (frequency over block) }\end{array}$ & 0.40 & $(0.06)^{* * *}$ & -10.46 & $(1.67)^{* * *}$ & 0.00 & $(0.14)$ \\
\hline $\begin{array}{l}\text { Empty deck C (dummy) } \\
\text { Empty deck D (frequency over block) }\end{array}$ & 0.47 & $(0.05)^{* * *}$ & -6.17 & $(4.43)$ & -1.07 & $(0.20)^{* * *}$ \\
\hline Empty deck D (dummy) & & & -7.75 & $(2.71)^{* *}$ & -0.88 & $(0.15)^{* * *}$ \\
\hline Card block CB & 0.03 & $(0.01)^{* *}$ & - & & - & \\
\hline $\begin{array}{l}\text { Card CN } \\
\text { Prior selection's RDA } \\
\text { Entrepreneurship }\end{array}$ & - & & 0.16 & $(0.84)$ & $\begin{array}{r}-0.23 \\
0.69\end{array}$ & $\begin{array}{l}(0.05)^{* * *} \\
(0.07)^{* * *}\end{array}$ \\
\hline $\begin{array}{l}\text { Entrepreneurial experience EE } \\
\text { Interactions }\end{array}$ & -0.03 & $(0.01)^{* * *}$ & 2.72 & $(0.49)^{* * *}$ & 0.09 & $(0.04)^{*}$ \\
\hline$\overline{\mathrm{EE} \times \mathrm{CB}}$ & -0.01 & $(0.01)$ & & & & \\
\hline $\mathrm{EE} \times \mathrm{CN}$ & & & 1.86 & $(0.71)^{* *}$ & -0.06 & $(0.04)$ \\
\hline Observations (subjects) & 1745 & $(349)$ & 31028 & $(349)$ & 31028 & $(349)$ \\
\hline $\mathrm{R}^{2} /$ Pseudo- $\mathrm{R}^{2}$ (Wald $\chi^{2}$ ) & 0.137 & $(270.59) * * *$ & 0.014 & $(84.60)^{* * *}$ & 0.032 & $(265.91)^{* * *}$ \\
\hline
\end{tabular}

Notes: OLS regressions $(1,2)$ and logistic regression (3) with cluster-bootstrapped (>2,000 repetitions) standard errors in parentheses. Because we have multiple observations per participant, there may be autocorrelation. The clustering procedure accounts for these effects. Other estimators, such as OLS and logistic regression with cluster-robust standard errors, yield similar results (available upon request). Herfindahl index (logarithm) is calculated for five blocks of twenty cards. Card number and card block are centered, i.e., between -1 for the first card/block and +1 for the last card/block. All significance levels are based on the normal approximation, but percentile-based bias-corrected and accelerated confidence intervals lead to equivalent levels of confidence. ${ }^{* * *} \mathrm{p}<0.001 ; * * \mathrm{p}<0.01 ; * \mathrm{p}<0.05 ;+\mathrm{p}<0.10$ 
TABLE 3:

\section{REGRESSION ANALYSES FOR ENTREPRENEURS AND COMPARISON GROUP}

\begin{tabular}{|c|c|c|c|c|c|c|}
\hline Model & \multicolumn{2}{|c|}{1} & \multicolumn{2}{|r|}{2} & \multicolumn{2}{|r|}{3} \\
\hline Dependent Variable & \multicolumn{2}{|c|}{$\begin{array}{c}\text { Concentration of } \\
\text { selections }(H I)\end{array}$} & \multicolumn{2}{|c|}{$\begin{array}{l}\text { Relative disadvantage of } \\
\text { selected deck }(R D A)\end{array}$} & \multicolumn{2}{|c|}{$\begin{array}{l}\text { Switching likelihood } \\
\text { (SW) }\end{array}$} \\
\hline Constant & -0.91 & $(0.11)^{* * *}$ & 26.64 & $(5.12) * * *$ & 0.12 & $(0.49)$ \\
\hline \multicolumn{7}{|l|}{ Demographic control variables } \\
\hline Age & 0.00 & $(0.00)$ & -0.00 & $(0.13)$ & -0.01 & $(0.01)$ \\
\hline Gender (female) & -0.06 & $(0.05)$ & -2.27 & $(2.56)$ & 0.44 & $(0.25)+$ \\
\hline \multicolumn{7}{|l|}{ Game control variables } \\
\hline Empty deck B (frequency over block) & -0.01 & $(0.26)$ & & & & \\
\hline Empty deck B (dummy) & & & -6.77 & $(6.32)$ & -0.27 & $(0.36)$ \\
\hline Empty deck C (frequency over block) & 0.42 & $(0.59)$ & & & & \\
\hline Empty deck C (dummy) & & & 14.21 & $(16.05)$ & -0.30 & $(0.94)$ \\
\hline Empty deck D (frequency over block) & 0.34 & $(0.20)+$ & & & & \\
\hline Empty deck D (dummy) & & & -13.93 & $(5.00)^{* *}$ & -0.65 & $(0.36)^{+}$ \\
\hline Card block CB & 0.11 & $(0.03)^{* * *}$ & & & & \\
\hline Card CN & & & -0.41 & $(1.93)$ & -0.30 & $(0.11)^{* *}$ \\
\hline Prior selection's RDA & & & & & 0.75 & $(0.16)^{* * *}$ \\
\hline Entrepreneurship & & & & & & \\
\hline $\begin{array}{l}\text { Entrepreneurs versus comparison group } \\
\text { Interactions }\end{array}$ & -0.24 & $(0.05)^{* * *}$ & 10.17 & $(2.29)^{* * *}$ & 0.71 & $(0.25)^{* *}$ \\
\hline $\mathrm{EE} \times \mathrm{CB}$ & -0.06 & $(0.04)$ & & & & \\
\hline $\mathrm{EE} \times \mathrm{CN}$ & & & 1.34 & $(2.74)$ & -0.23 & $(0.22)$ \\
\hline Observations (subjects) & 500 & $(100)$ & 8891 & $(100)$ & 8891 & $(100)$ \\
\hline $\mathrm{R}^{2}\left(\right.$ Wald $\left.\chi^{2}\right)$ & 0.136 & $(64.63)^{* * *}$ & 0.021 & $(42.71)^{* * *}$ & 0.048 & $(72.52) * * *$ \\
\hline
\end{tabular}

Notes: OLS regressions $(1,2)$ and logistic regression (3) with cluster-bootstrapped $(>2,000$ repetitions) standard errors in parentheses. Because we have multiple observations per participant, there may be autocorrelation. The clustering procedure accounts for these effects. Other estimators, such as OLS and logistic regression with cluster-robust standard errors, yield similar results (available upon request). The Herfindahl index (logarithm) is calculated for five blocks of twenty cards. Card number and card block are centered, i.e., between -1 for the first card/block and +1 for the last card/block. All significance levels are based on the normal approximation, but percentile-based bias-corrected and accelerated confidence intervals lead to equivalent levels of confidence. $* * * \mathrm{p}<0.001 ; * * \mathrm{p}<0.01 ; * \mathrm{p}<0.05 ;+\mathrm{p}<0.10$ 
FIGURE 1: EXAMPLE SCREENSHOT

Starting total: 2000

Total gains: 550

Total losses: 50

Current total: 2500
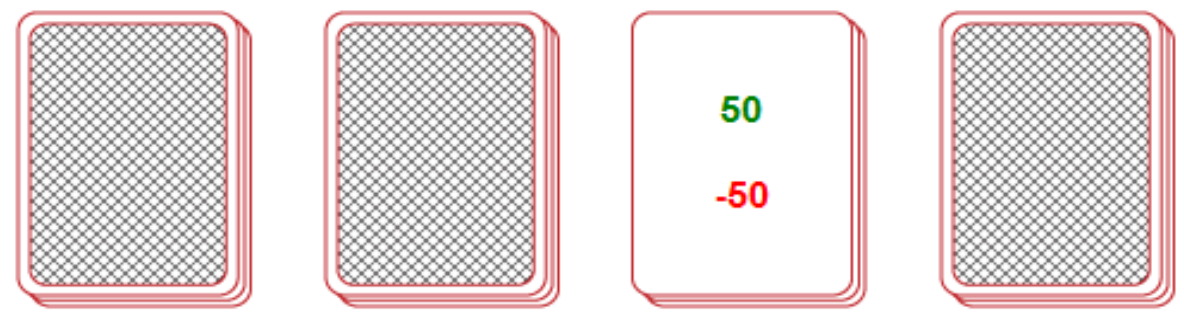
FIGURE 2:

DESCRIPTIVES FOR FOUR GROUPS IN BLOCKS OF 20 SELECTIONS EACH [MEAN, STANDARD ERROR]
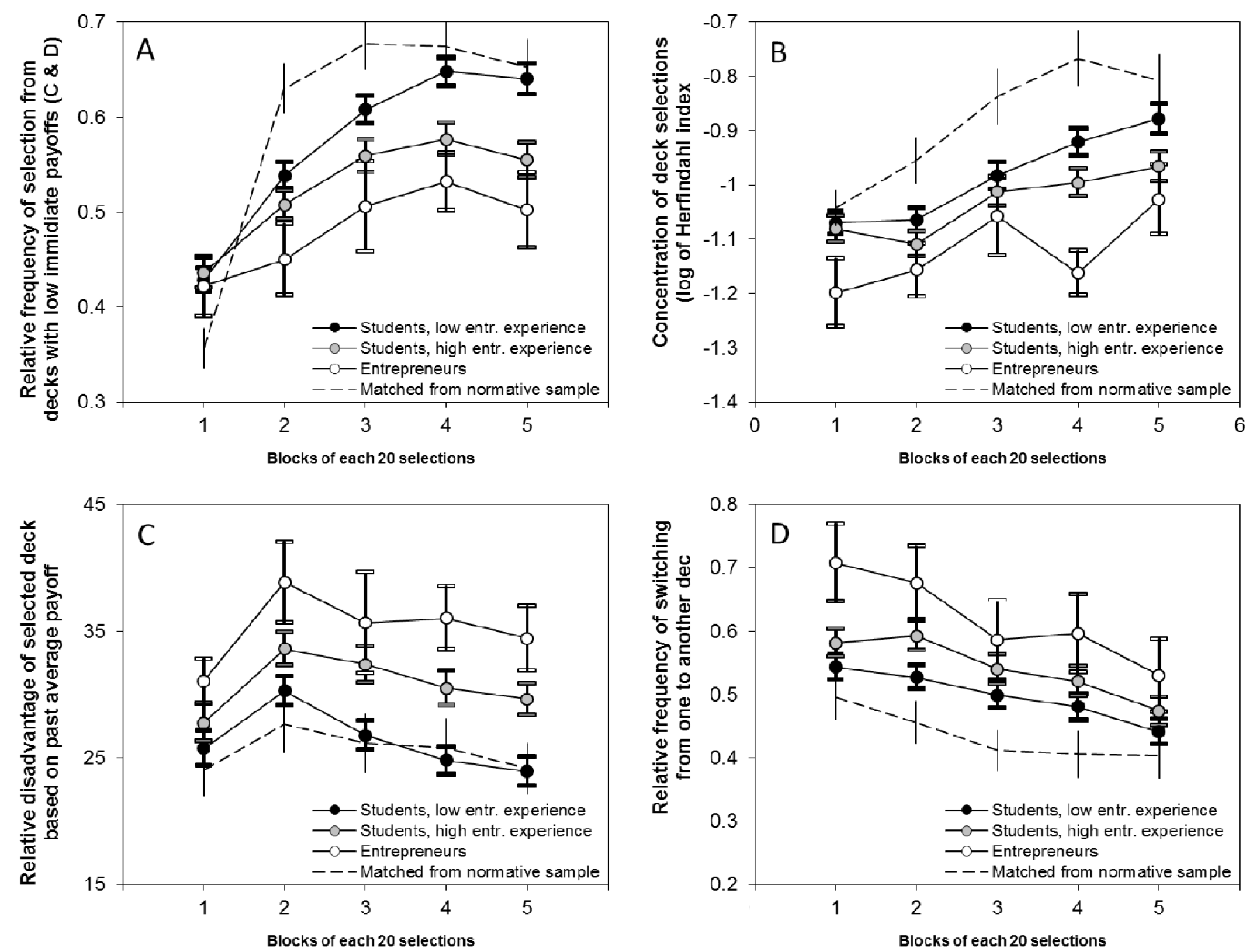